\title{
ENCLAVES Y ESPACIOS INTERNODALES EN LA DINÁMICA DE POBLACIONES EN EL WALL-MAPU. APORTES DESDE LA ARQUEOLOGÍA PAMPEANA
}

\author{
LOCATIONS AND INTERNODAL SPACES IN THE DYNAMICS OF \\ POPULATIONS IN THE WALL-MAPU. CONTRIBUTIONS FROM \\ PAMPEAN ARCHEOLOGY
}

\author{
Mónica Berón ${ }^{1}$, Ayelen Di Biase², M. Gabriela Musaubach y Florencia Páez ${ }^{4}$
}

\begin{abstract}
Resumen
Distintas líneas de evidencia abordadas desde la investigación arqueológica del centro de Argentina, particularmente en la Provincia de La Pampa, dan cuenta de la existencia de un corredor bioceánico de interacción, movilidad y fuerte dinámica social entre los actuales territorios de Chile y Argentina ( $36^{\circ}$ a $39^{\circ}$ L.S.). El objetivo de este trabajo es discutir acerca de los procesos de interacción y conflicto que han quedado plasmados en los espacios nodales, pero que sin duda tuvieron escenarios geográficos en las regiones internodales de este amplio corredor. La información generada a través de la investigación arqueológica, análisis de fuentes etnohistóricas y de testimonios etnográficos permiten proponer que durante el Holoceno Tardío (últimos 2 mil años) se generó un corredor de interacción entre grupos cazadores-recolectores de la zona central de Argentina, alcanzando sectores trascordilleranos y contribuyendo a la integración territorial del Wall-Mapu.
\end{abstract}

Palabras claves: Corredor bioceánico norpatagónico - interacción conflicto - enfoque transdiciplinar.

\begin{abstract} Different approaches to the analysis of archaeological evidence in the center of Argentina, particularly in La Pampa province, account for the existence of a bi-oceanic corridor that favored the interaction, mobility and a strong social dynamic between the current territories of Chile and Argentina ( $36^{\circ}$ to $\left.39^{\circ} \mathrm{LS}\right)$. The aim of this paper is to discuss the processes of interaction and conflict that have been shaped in the nodal spaces, but that certainly had geographical settings in the interno$\mathrm{dal}$ regions of this broad corridor. The information originated through

archaeological research, analysis of ethnohistorical documents and ethnographic testimonies allow to propose that during the Late Holocene (last 2000 years) a corridor of interaction between groups of hunter-gatherers in central Argentina, was generated, reaching to trans-Andean sectors and contributing to territorial integration of the
\end{abstract} Wall-Mapu.

Keywords: North-patagonic bi-oceanic corridor - interaction conflict - transdisciplinary approach.

\section{* Introducción}

Distintas líneas de evidencia abordadas desde la investigación arqueológica del centro de la Argentina, particularmente en la Provincia de La Pampa, dan cuenta de la existencia de un "corredor bioceánico norpatagónico" de interacción, movilidad y fuerte dinámica social (Berón 2005, 2007a y b, 2013a). Dicho corredor es un amplio territorio que se extiende entre los actuales países de Argentina y Chile, de un océano al otro, surcado por caminos y rutas que permiten un flujo permanente de poblaciones, mercaderías y cultura, desde tiempos prehispánicos hasta el presente (Bandieri 2005; Bello 2011; Zavala Cepeda 2011; Nicoletti y Núñez 2013; Hajduk et al. 2011). Los pueblos prehispánicos que habitaban estos territorios se definían en función de las posiciones geopolíticas estratégicas, según el momento histórico y las alianzas o divergencias que tuvieran con otras poblaciones cercanas.

El territorio que atraviesa este corredor es denominado desde la cosmología mapuche como Wall-Mapu o WajMapu (Figura 1). El Wall-Mapu es el territorio mapuche o "país mapuche", y se ha convertido en la actualidad en uno de los símbolos de lucha de este pueblo, como una forma más de expresión cultural, más allá de ser considerado como un espacio en el que históricamente obtuvieron su subsistencia (Radovich 2003).

Recibido: marzo 2016. Aceptado: diciembre 2016.

\footnotetext{
1 Universidad de Buenos Aires, Consejo Nacional de Investigaciones Científicas y Técnicas, Instituto de las Culturas, Facultad de Filosofía y Letras, Museo Etnográfico J. B. Ambrosetti. Moreno 350, C.A.B.A., ARGENTINA. Email: monberon@retina.ar

2 Universidad de Buenos Aires, Agencia Nacional de Promoción Científica y Tecnológica, Instituto de las Culturas, Facultad de Filosofía y Letras, Museo Etnográfico J. B Ambrosetti. Moreno 350, C.A.B.A., ARGENTINA. Email: ayeayeantropo@yahoo.com.ar

3 Universidad de Buenos Aires, Consejo Nacional de Investigaciones Científicas y Técnicas, Instituto de las Culturas, Facultad de Filosofía y Letras, Museo Etnográfico J. B. Ambrosetti. Moreno 350, C.A.B.A., ARGENTINA. Email: gabrielamusa@gmail.com

4 Museo Etnográfico Juan B. Ambrosetti, Facultad de Filosofía y Letras, UBA. Moreno 35o, C.A.B.A., ARGENTINA. Email: fnatapaez@gmail.com
} 


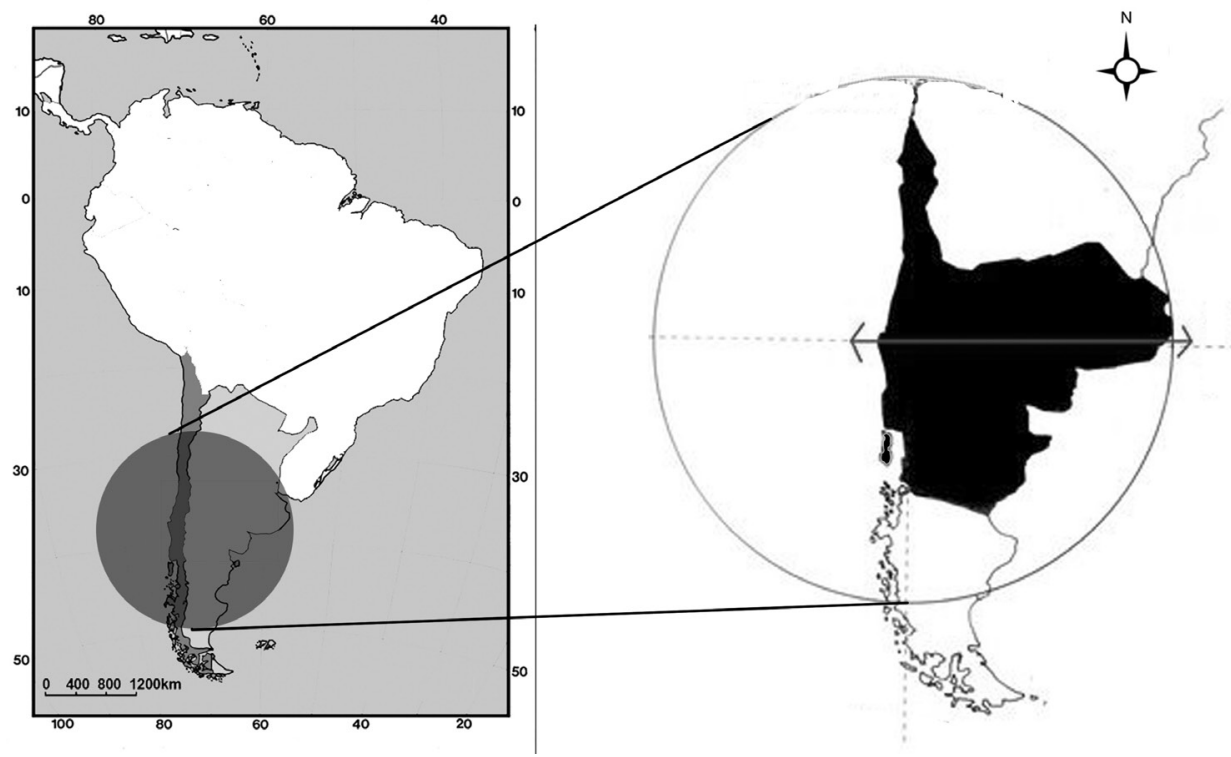

Figura 1. Mapa del Wall-Mapu tomado y modificado de la figura del Dr. Bahamonde Paillallef. Área mínima del territorio mapuche considerando la extensión del mapuzungum según Erize (1987).

Si bien no asumimos una continuidad histórica entre los pueblos prehispánicos mencionados y los actuales pueblos originarios, el registro arqueológico que tomaremos como referencia se ubica dentro del Wall-Mapu. El área de investigación arqueológica es la Pampa Occidental, ubicada en el sector meridional de la Provincia de La Pampa (Argentina). Corresponde a un ambiente semidesértico que comprende unos 100 mil kilómetros cuadrados con un régimen de lluvias entre 500 y 200 $\mathrm{mm}$ anuales. En este territorio vivieron poblaciones cazadoras-recolectoras desde hace 9 mil años, aunque no en forma continua, ni espacial ni temporalmente. Su régimen de asentamiento y movilidad ha estado fuertemente sujeto a la disponibilidad de fuentes de agua potable y de otros recursos disponibles en estos ambientes. Pero también se registran discontinuidades y hiatos en el uso de los paisajes debido a factores de perturbación que afectan la integridad del registro arqueológico. Por eso se ha registrado una sola cronología correspondiente al Holoceno Temprano (ca. 8600 años $\mathrm{AP})$, un bache de información entre ca. 6500 y $5500 \mathrm{BP}$ y un repoblamiento continuo a partir de los ca. 5000 años AP (Berón 2015).
Durante los últimos 2 mil años se registra un crecimiento demográfico, así como indicadores crecientes de interacciones a media y larga distancia, incluso transponiendo la cordillera andina. Dichas interacciones adoptaron dinámicas diversas y cambiantes que incluyeron relaciones de parentesco, alianzas político-sociales y conflictos, en escenarios geográficos con características diversas. Estos temas han sido abundantemente tratados por nosotros en trabajos previos (Berón 2004, 2007b, 2014; Salazar Siciliano y Berón 2013; Musaubach y Berón 2012; Berón et al. 2015).

Un rasgo característico de las zonas áridas y semiáridas, es que la densidad de población en estos territorios es generalmente muy baja (Veth 1995) y presentan nodos de agregación de población, casi siempre en relación a puntos destacados del paisaje, en cercanía a algún tipo de recurso vital, separados por amplias áreas casi despobladas (Berón 2016; Thackeray 2005; Veth 1995). La mayor parte de las actividades humanas y la vida social se aglomera y condensa en estos nodos.

El estudio de los llamados espacios internodales o intersticiales pretende conocer cómo estos espacios nos informan acerca de las relaciones entre sociedades a escala local, 
regional e interregional (Berenguer y Pimentel 2010). Su análisis puede ayudarnos a comprender la historia, la naturaleza y la dinámica de las ocupaciones humanas en las zonas áridas y semiáridas (Berenguer 2004).

El objetivo del trabajo es discutir los procesos de interacción y conflicto que han quedado plasmados en los espacios nodales, pero que sin duda tuvieron escenarios geográficos en las regiones internodales de este amplio corredor. En este sentido, entenderemos como internodales aquellos espacios de contacto intersocietal, redes de caminos indígenas o "rastrilladas" y pasos cordilleranos que unían los actuales territorios de Chile y Argentina. La integración macrorregional era posible a partir del establecimiento de estos espacios internodales, que conectaban a las sociedades.

\section{* Conceptualización espacial del wall-mapU (WAJ-MAPU)}

Muchos investigadores han visto a lo largo del tiempo a la cultura mapuche como portadora de una identidad homogénea, cuya organización fue el producto final de la injerencia colonial. En oposición a esto, consideramos que la identidad de los pueblos originarios, lejos de ser un mero producto de la resistencia colonial, es una posición negociada y muchas veces contradictoria entre la capacidad de subordinarse y la de resistir de un pueblo (Dillehay 2002). “...la identidad mapuche puede ser vista no solamente como normativa sino transformativa, en la medida en que refleja la tensión entre la construcción recibida de la historia cultural e identidad, y las reales o más completas condiciones históricas" (Dillehay 2002: 167). Dillehay (2002, 2011) señala que los espacios ceremoniales juegan un rol importante en la reproducción del pasado y sustento de la integridad cultural presente, a partir de estudios arqueológicos, sociolingüísticos, etnohistóricos y etnográficos, propios y anteriores, sobre economía y organización social, para describir la trayectoria evolutiva de largo plazo de esas sociedades y el concepto mapuche de paisaje cultural e identidad, como parte de un proceso histórico. Este pensamiento es acorde a la posición que adoptamos respecto de la idea de identidad, y nos allana el camino para poder hablar acerca de la conceptualización espacial del Wall-Mapu.

Asimismo, existen análisis que consideran como mapuches a la totalidad de los grupos indígenas mapudungun- hablantes, mientras que otros entienden como tales solo a los grupos de la Araucanía (Zavala Cepeda 2011). Consideramos la primera opción como válida, ya que incluiría también a los grupos que ocupaban los actuales territorios de pampa y norpatagonia, de los que se ocupa este escrito.

Zavala Cepeda (2011) considera que ya para el siglo XVIII entre los mapuches existe "un circuito de intercambios que relaciona, a través de La Pampa y de los Andes, la costa atlántica con la costa pacífica; este circuito es controlado por los mapuches y pone en contacto a diversos grupos que se desplazan para intercambiar" (Zavala Cepeda 2011: 20). Luego destaca que algo que los caracterizó y les aportó continuidad histórica fue su capacidad de cambiar, de metamorfosearse, de adaptarse, incorporando elementos culturales de diferente origen, a modo de "transferencias culturales" que, lejos de favorecer su subordinación, contribuyó a reafirmar su identidad, otorgándoles medios de resistencia y perpetuando sus diferencias respecto a otros (Zavala Cepeda 2011).

\section{Dinámica poblacional en el Wall-Mapu}

En las latitudes consideradas ( $32^{\circ}$ a $39^{\circ}$ L.S.), los Andes no se comportan como una frontera infranqueable, sino que sus características de transitabilidad permiten resignificar el concepto de frontera, como un espacio constantemente recreado por las sociedades implicadas en los territorios de su entorno. Esta dinámica fue posible gracias a la baja altitud del macizo montañoso en algunos puntos específicos y a la existencia de numerosos pasos trascordilleranos. Las referencias etnográficas actuales respecto a las actividades que se desarrollan en los mismos, son datos claves que indican la importancia que tenían como rutas de contacto permanente entre poblaciones durante milenios (Berón 2006, 2007b, 2013a).

Es así que la presencia mapuche en los actuales territorios de La Pampa es un fenómeno tan antiguo como progresivo, el cual siguió diversas vertientes y se desarrolló con mayor celeridad a partir del siglo XVIII (Zavala Cepeda 2011). Desde el registro arqueológico la existencia de circuitos de intercambios interandinos data por lo menos desde el siglo XI (Berón et al. 2012; Mera et al. 2015). Desde el registro etnohistórico se pueden rastrear transacciones desde al menos el siglo XVI, como por ejemplo Vivar, quien señala 
que "en 1558 los puelches descendían de los Andes hacia Chile para intercambiar mantas de piel de guanaco y plumas de ñandú" (Zavala Cepeda 2011: 50).

Ya en el siglo XIX diversos autores hablan de la consolidación del dominio mapuche sobre la provincia de La Pampa. Cabe señalar que las relaciones entre los grupos de La Pampa y los mapuches de las tierras bajas de Chile son recurrentemente narradas a partir de este siglo, en fuentes de la época como Luis de la Cruz o Lucio Mansilla. Según Zavala Cepeda (2011), "los mapuches dominan ya completamente las relaciones con los blancos, y controlan los intercambios blancos-indígenas [...] y se encuentran presentes tanto en las fronteras de Chile (Araucanía y Valdivia) como en las de Argentina (Mendoza y Buenos Aires)" (Zavala Cepeda 2011: 58).

La existencia de un movimiento histórico de expansión hacia el este llevado a cabo desde los inicios de los tiempos prehispánicos hasta el siglo XIX, por parte de las poblaciones mapuches, fue acompañada de una intensificación de los circuitos de intercambio trascordilleranos de toda índole. Ello nos lleva ineludiblemente a la necesidad de conceptualizar desde la cosmología mapuche, la idea de espacio-territorio para remitirnos luego a la evidencia arqueológica y a los espacios internodales que se intenta analizar.

Según la coordinadora de organizaciones mapuches de Neuquén, las organizaciones indígenas regionales conciben el territorio como

...el espacio en el que se desarrolla la cultura Mapuche, el cual comprende como un todo (Waj-Mapu) los recursos naturales, la superficie (Xufken-Mapu) y el subsuelo (Minche-Mapu) de la tierra, el aire (Wenu-Mapu), la historia de sus relaciones sociales, culturales, filosóficas y económicas, como también su evolución. En el territorio no existen las partes sino las continuas relaciones entre ellas, que conforman el Todo (Waj-Mapu o Wall-Mapu) (Coordinadora de Organizaciones Mapuche 2001: 1).

El Wall-Mapu o Waj-Mapu (tierra circundante) es concebido como la base de la existencia y cultura mapuche. Este amplio territorio está localizado en el centro sur del territorio chileno y argentino, separado por la cordillera de los Andes o Pire-Mapu. Al oeste del macizo montañoso se encuentra el Ngulu-Mapu y al este, el Puel-Mapu.
La concepción espacial, según la cosmogonía mapuche, remite a los cuatro puntos cardinales. El este o Puel-Mapu está asociado a los dioses, antepasados, espíritus benéficos y a la buena suerte. Los elementos vinculados son el buen viento, tiempo, trabajo, cosecha, abundancia y salud. El sur o Willi-Mapu está asociado a la buena suerte y a los mismos elementos que el Puel-Mapu. El Piku-Mapu o norte está vinculado, por el contrario, a la mala suerte y a elementos como el viento norte, mal tiempo, lluvia, agua, trueno, enfermedad, muerte. El Lafken/Nau-Mapu u oeste, asociado al espíritu del mal o Wekufe, mala suerte, mal, está vinculado a elementos como la oscuridad, el viento malo, temporal, maremoto, lluvia mala, nieve, heladas, enfermedad y muerte (C.N.C.A. 2012).

La división identitaria y territorial de los actuales territorios de pampa y norpatagonia puede esquematizarse de la siguiente manera: los puelches o Gente del Este, se habían establecido en las tierras de Tapalqué, Azul, los Huesos, Tandil y del Tuyú, Sierra de la Ventana, Curamalal, Guaminí y el Río Negro. Los voroas (voroganos) ocupaban las Salinas Grandes, en la Cañada de los Manantiales, comprendiendo a su vez los territorios de Carhué a Chadileuvú y de Naicó al Colorado, los valles de Quehué, Utracán, Maracó Grande, Maracó Chico y Ucal (Provincia de La Pampa). Los rankulches residían en el norte de La Pampa, sur de San Luis y Córdoba, con Leuvucó como su centro principal, Poitahué, territorio conocido como Mamül-Mapu. Los pehuenches moraban en la precordillera del sur de Mendoza hasta Chadileuvú. Los huilliches vivían al sudeste de los pehuenches, mientras que los picunches lo hacían al norte de aquéllos. Por último, los tehuelches se habían establecido en los territorios que iban de Choele Choel hasta el estrecho de Magallanes. Esta etnia, de amplia dispersión geográfica, ha sido motivo de diferenciaciones lingüístico-territoriales establecidas por algunos autores y discutidas por otros (Casamiquela 1965, 1969, 1985; Nacuzzi 2005). Sin embargo es importante explicitar que debido a la gran movilidad e intercambio de dichos grupos, se vuelve arbitrario nomenclarlos de una forma definitiva, ya que muchas veces cambiaban sus nombres y/o adaptaban los de sus caciques (Erize 1987; Nacuzzi 2005).

Si bien el interés de este trabajo se centra en tiempos prehispánicos y coloniales, los grupos arriba mencionados han logrado sobrevivir al genocidio y etnocidio 
perpetrado por parte del Estado Nacional Argentino hacia finales del siglo XIX, durante el proceso de conformación del mismo (Bartolomé 2003). Es así que hoy en día muchos viven aún en sus territorios ancestrales, pero otros han emigrado a las grandes ciudades del país en busca de mejores condiciones socioeconómicas de desarrollo, en particular a partir de la mitad del siglo XX (Weiss et. al. 2013).

El principal foco de interés de este trabajo es el denominado Mamül-Mapu o país del monte, locación en la que viven las poblaciones ranqueles o rankulches ("gente del carrizal" en rankul), quienes fueron tradicionalmente grupos de gran movilidad (Dos Santos Montangie 2014). Tal como lo expresa un dirigente rankulche:

"Siempre estuvimos aquí. Vinieron de otros pueblos. Algunos sumaron, otros restaron. Se produjo así una gran experiencia multicultural y multilinguística entre nosotros, los hermanos del norte que escapaban del invasor español. Ylos del sury del oeste porvecindad y comercio, parentesco" (Canuhé 1998).

Asimismo, el citado líder rankulche expresa que, de acuerdo a las crónicas de Luis de la Cruz en el año 1806, las divisiones sociopolíticas de lo que consideramos WallMapu consistían en la Gente de los Pinares o pehuenches, los thue-huili che del norte, los thue-huili che del sur, mientras que en el centro estaban los mamulche o aquellos que viven en el País del Monte. Su dominio iba del río Salado y río Cuarto hasta el río Negro, sur de Santa Fe, Córdoba, San Luis, Mendoza y parte de Neuquén. Según Canuhé, fue el líder Carripilún, al que apodaban "el ranquelino", quien debido a "su capacidad y sabiduría [...] hizo mimetizar ambos términos: mamulche y rankulche (Ranquel che)" (Canuhé 1998).

La concepción espacial de los pueblos mapuche y rankulche entonces, debe ser tenida en cuenta en su complejidad, a la hora de pensar tanto los nodos principales como los espacios internodales del área de interés de esta investigación.

\section{Correlato arqueológico}

La evidencia material en la vertiente occidental cordillerana está dando cuenta cada vez con mayor énfasis, del correlato de estos procesos de contactos y dinámica social en el sector chileno del área considerada, coincidentes tanto en la escala espacial como cronológica (Stern et al. 2009; Mera et al. 2015; Hajduk et al. 2011; Adán et al. 2005, 2010; Bahamondes y Correa 2008; Donoso y Gallego 2010; Salazar Siciliano y Berón 2013; Berón et al. 2013). Dicha integración regional, se evidencia desde tiempos prehispánicos (Holoceno Tardío final ca. 2.000 años AP), continuando en el presente entre los actuales territorios de Chile y Argentina, especialmente entre los $36^{\circ}$ a $39^{\circ}$ L.S. (Berón et al. 2012; Salazar Siciliano y Berón 2013; Musaubach et al. 2015).

La zona en estudio comprende cinco áreas arqueológicas de la Pampa Occidental. Dentro del territorio pampeano los análisis se centrarán en el registro arqueológico de las áreas del Curacó, Lihué Calel, Valles Transversales y Bajos sin Salida en el sudeste y Meseta Basáltica y área Casa de Piedra en el sudoeste (Figura 2). En cada una de estas áreas se han localizado distintos tipos de sitios arqueológicos o concentraciones de ellos a los que denominamos, en este último caso, Localidades Arqueológicas. Dichas localidades son nuestros nodos, espacios de uso recurrente y con diferente funcionalidad. Tres de estos nodos son los que han permitido establecer secuencias cronológicas de los procesos culturales. Ellos son la localidad arqueológica Lihué Calel, y en particular el Sitio Chenque I, cementerio de uso consuetudinario a lo largo de ca. 800 años; la Localidad Tapera Moreira, que concentra sitios de campamentos base de uso recurrente y enterratorios aislados, desde fines del Holoceno Medio hasta el Holoceno Tardío final. El tercero es la Localidad San Sixto, que reúne siete sitios tanto de enterratorio como de actividades múltiples. En la Tabla 1 se sintetizan dentro de cada área arqueológica, los nodos y sus características más relevantes.

Como se mencionó en los párrafos precedentes, la interacción entre las sociedades que habitaron en ambas vertientes de la cordillera de los Andes es de larga data. La misma ha quedado registrada a partir de la materialidad de los sitios arqueológicos prehispánicos identificados en la franja que comprende los actuales territorios de Chile centro-sur y Argentina central. Por ejemplo, materias primas líticas alóctonas como la obsidiana y cerámica de procedencia chilena, tienen una amplia distribución en el registro arqueológico trasandino (Falabella et al. 2001). En el caso de la obsidiana, han sido identificadas fuentes tanto en el lado argentino -El Pehuenche, Las Cargas, La 


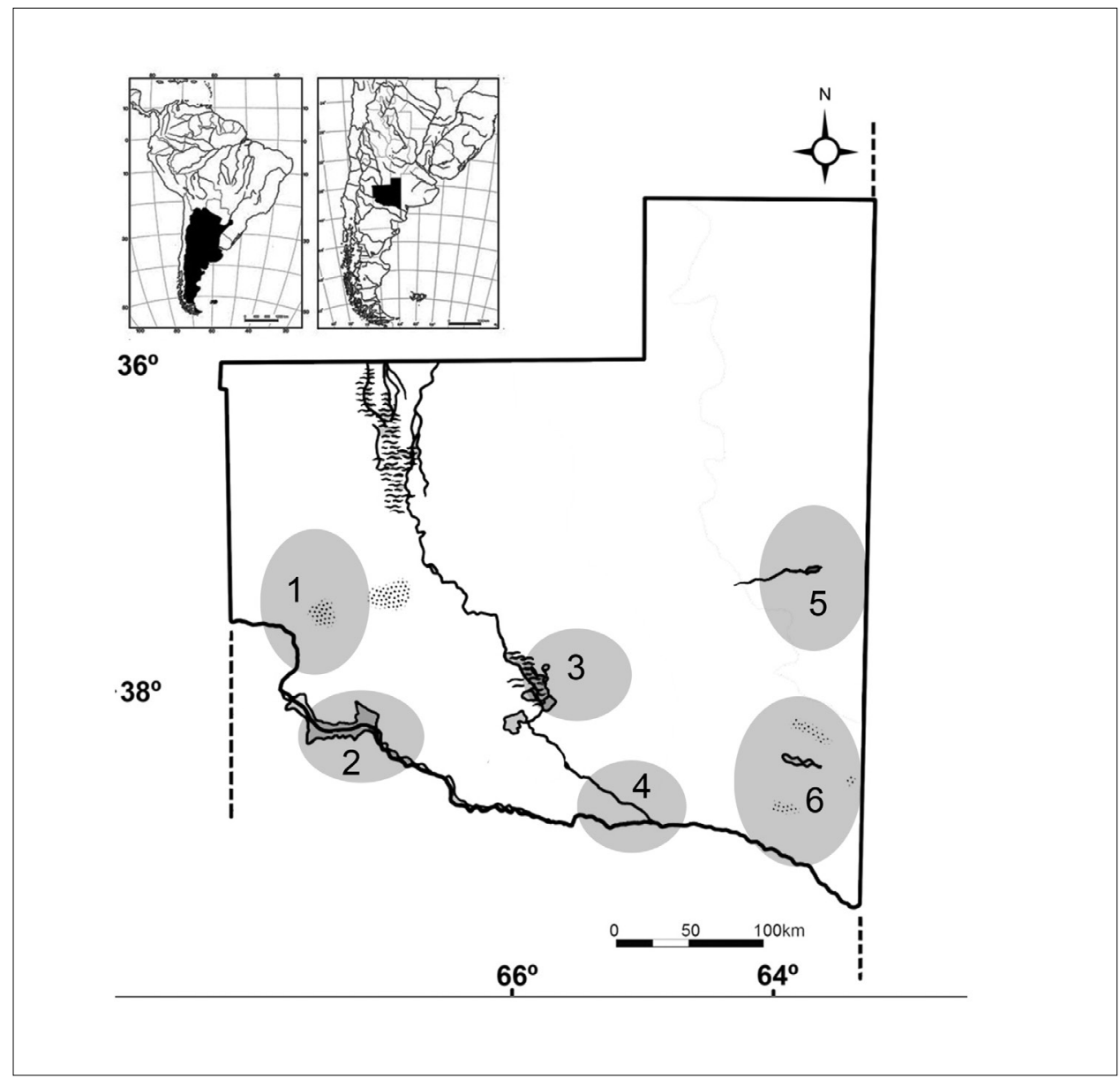

Figura 2. Mapa con las áreas arqueológicas abordadas en este trabajo. 1-Meseta Basáltica. 2- Casa de Piedra. 3Sierras de Lihué Calel. 4- Cuenca del Curacó. 5-Valles Transversales. 6- Bajos sin Salida. A- Localidad Arqueológica Lihué Calel, B- Localidad Arqueológica Tapera Moreira y C- Localidad Arqueológica San Sixto.

Bandera, entre otras-, como en el lado chileno la fuente de la Laguna del Maule (Neme y Gil 2005; Durán et al. 2004; Stern et al. 2009, entre otros).

Por su parte, ha resultado diagnóstica de la extensión espacial de la interacción la cerámica con decoración acanalada o con estriamientos anulares (challas), cuya distribución en la vertiente oriental de los Andes, incluye principalmente sitios de la Provincia de Neuquén, en la zona de Aluminé, Montículo Angostura, Cueva Haichol y sitios del valle del Malleo (Hajduk 1986; Fernández 1988-1990; Goñi 1986-1987; Salazar Siciliano y Berón 2013), cuenca del río Limay (Crivelli 2008) y otros sitios y conjuntos mencionados en Hajduk et al. (2011). Su presencia en el centro de La Pampa (Tabla 1) y en sitios de las sierras de Tandilla (Mazzanti 2007), ha sido identificada como extrarregional.

En cuanto a los sitios de la Araucanía chilena, este tipo particular de decoración fue registrado en sitios de la zona de El Vergel, en las cercanías de Angol (Bullock 1970), en los sitios Casa Fuerte Santa Sylvia (Gordon 1991), sitios del Alto Biobío (Cáceres et al. 2005), Aleros de Purranque 1, 2, 3 y Alero Cabeza de Indio-1 (Bahamondes y Correa 2008; Stern et al. 2009), y Carilafquén-1, en la comuna de Melipeuco (Donoso y Gallego 2010).

Otra cerámica de indudable procedencia transcordillerana es la correspondiente a la Tradición Bícroma (Adán et al. 2005), que ha sido localizada en el sitio Rinconada Giles, 
ENCLAVES Y ESPACIOS INTERNODALES EN LA DINÁMICA DE POBLACIONES EN EL WALL-MAPU. APORTES DESDE LA ARQUEOLOGÍA PAMPEANA

Tabla 1. Síntesis de las áreas arqueológicas de la Pampa Occidental analizadas en este trabajo. Se resumen las principales características discriminadas por nodo. Referencias: L: local, Exr: extrarregional, Cer: Cerámica, Estr: Estructura.

\begin{tabular}{|c|c|c|c|c|c|c|c|c|c|c|c|}
\hline $\begin{array}{c}\text { Área } \\
\text { arqueológica }\end{array}$ & Departamento & \multicolumn{2}{|c|}{$\begin{array}{l}\text { Nodos: Localidad/ } \\
\text { Sitio Arqueológico }\end{array}$} & $\begin{array}{l}\text { Cronología años } \\
\text { AP/Relativa }\end{array}$ & $\begin{array}{c}\text { Rasgo } \\
\text { topográfico }\end{array}$ & $\begin{array}{l}\text { Entierros } \\
\text { humanos }\end{array}$ & $\begin{array}{c}\mathrm{MP} \\
\text { lítica }\end{array}$ & Cer. & $\begin{array}{c}\text { Adorno/ } \\
\text { Arte } \\
\text { rupestre }\end{array}$ & $\begin{array}{l}\text { Estr. de } \\
\text { piedra }\end{array}$ & Fuente \\
\hline \multirow{18}{*}{ 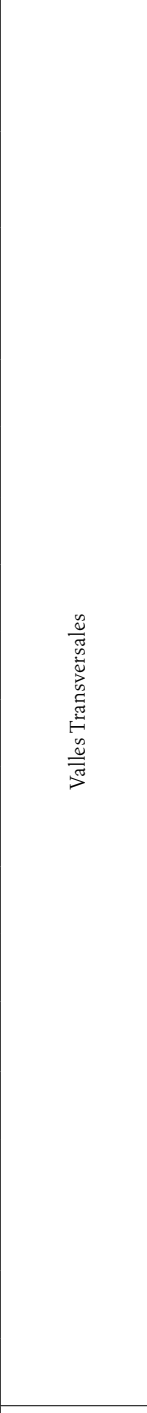 } & \multirow{6}{*}{ Atreucó } & \multicolumn{2}{|c|}{ Médanos de Costilla } & - & $\begin{array}{c}\text { Médano - } \\
\text { Laguna }\end{array}$ & - & L-Exr & $\mathrm{L}$ & tupu latón & - & $\begin{array}{l}\text { Berón et } \\
\text { al. } 2015 \\
\end{array}$ \\
\hline & & \multicolumn{2}{|c|}{$\begin{array}{c}\text { Médanos de } \\
\text { Phaguapé }\end{array}$} & - & Médano & - & L-Exr & - & - & - & $\begin{array}{l}\text { Berón et } \\
\text { al. } 2015 \\
\end{array}$ \\
\hline & & \multicolumn{2}{|c|}{ Salinas Grandes } & - & $\begin{array}{l}\text { Laguna - } \\
\text { Salina }\end{array}$ & - & L-Exr & - & - & - & $\begin{array}{l}\text { Berón et } \\
\text { al. } 2015\end{array}$ \\
\hline & & \multicolumn{2}{|c|}{$\begin{array}{l}\text { Médanos de } \\
\text { Alduncín }\end{array}$} & - & Médano & - & L-Exr & - & $\begin{array}{l}\text { preforma de } \\
\text { cuenta de } \\
\text { mineral de } \\
\text { cobre }\end{array}$ & - & $\begin{array}{l}\text { Berón et } \\
\text { al. } 2015\end{array}$ \\
\hline & & \multicolumn{2}{|c|}{ La Cascada } & - & Laguna & - & L-Exr & - & - & - & $\begin{array}{l}\text { Berón et } \\
\text { al. } 2015 \\
\end{array}$ \\
\hline & & \multicolumn{2}{|c|}{ Bajo de Atreucó } & - & Bajo & - & L-Exr & - & - & - & $\begin{array}{l}\text { Berón et } \\
\text { al. } 2015 \\
\end{array}$ \\
\hline & Guatraché & \multicolumn{2}{|c|}{$\begin{array}{c}\text { Laguna Chillhué } \\
\text { (Sitios 1,2 y3) }\end{array}$} & $\begin{array}{c}1930 \pm 30(\text { UGAMS } \\
02009)\end{array}$ & Laguna & $\begin{array}{c}\text { Enterratorio } \\
\text { aislado }\end{array}$ & L-Exr & $\mathrm{L}$ & 一 & - & $\begin{array}{l}\text { Berónet } \\
\text { al. } 2006\end{array}$ \\
\hline & \multirow{11}{*}{ Hucal } & \multicolumn{2}{|c|}{ Laguna La Tigra } & $\begin{array}{c}590 \pm 20 \text { (UGAMS } \\
021347)\end{array}$ & Laguna & $\begin{array}{c}\text { Enterratorio } \\
\text { aislado }\end{array}$ & L-Exr & - & - & - & $\begin{array}{l}\text { Berón et } \\
\text { al. } 2015 \\
\end{array}$ \\
\hline & & \multirow{3}{*}{ 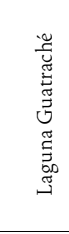 } & $\begin{array}{c}\text { Laguna } \\
\text { Guatraché }\end{array}$ & 一 & Laguna & - & L-Exr & L-Exr. & - & - & $\begin{array}{l}\text { Berón et } \\
\text { al. } 2015 \\
\end{array}$ \\
\hline & & & Balneario & - & Laguna & - & L-Exr & - & - & - & $\begin{array}{l}\text { Berón et } \\
\text { al. } 2015 \\
\end{array}$ \\
\hline & & & $\begin{array}{c}\text { Barranca } \\
\text { Blanca y La } \\
\text { Isla } \\
\end{array}$ & - & Laguna & - & L-Exr & - & - & - & $\begin{array}{l}\text { Berón et } \\
\text { al. } 2015\end{array}$ \\
\hline & & \multirow{7}{*}{ 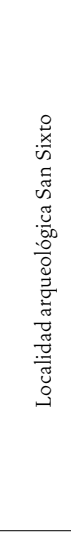 } & El Carmel & $\begin{array}{c}890 \pm 20 \text { (UGAMS } \\
021347)\end{array}$ & Médano & $\begin{array}{c}\text { Enterratorio } \\
\text { aislado }\end{array}$ & L-Exr & $\mathrm{L}$ & - & - & $\begin{array}{l}\text { Berón et } \\
\text { al. } 2015 \\
\end{array}$ \\
\hline & & & $\begin{array}{c}\text { Médano de } \\
\text { San Sixto }\end{array}$ & - & Médano & - & L-Exr & - & - & - & $\begin{array}{l}\text { Berón et } \\
\text { al. } 2015 \\
\end{array}$ \\
\hline & & & $\begin{array}{c}\text { Bajo de } \\
\text { Marcelino }\end{array}$ & - & Bajo & - & L-Exr & - & $\begin{array}{c}\text { cuentas de } \\
\text { valva }\end{array}$ & - & $\begin{array}{l}\text { Berón et } \\
\text { al. } 2015 \\
\end{array}$ \\
\hline & & & Luis Otero & - & - & - & L-Exr & $\mathrm{L}$ & - & - & $\begin{array}{l}\text { Berón et } \\
\text { al. } 2015 \\
\end{array}$ \\
\hline & & & $\begin{array}{c}\text { La } \\
\text { Tranquera }\end{array}$ & $\begin{array}{c}830 \pm 20 \text { (UGAMS } \\
021346)\end{array}$ & - & $\begin{array}{c}\text { Enterratorio } \\
\text { aislado }\end{array}$ & 一 & & - & - & $\begin{array}{l}\text { Diana et } \\
\text { al. } 2014 \\
\text { Berón et } \\
\text { al. } 2015 \\
\end{array}$ \\
\hline & & & $\begin{array}{c}\text { Bajada La } \\
\text { Minnesota }\end{array}$ & - & - & - & L-Exr & $\mathrm{L}$ & tembetá & - & $\begin{array}{l}\text { Berón et } \\
\text { al. } 2015 \\
\end{array}$ \\
\hline & & & $\begin{array}{l}\text { Médano La } \\
\text { Minnesota }\end{array}$ & - & Médano & Cementerio & L-Exr & - & $\begin{array}{c}\text { cuentas de } \\
\text { valva }\end{array}$ & - & $\begin{array}{l}\text { Berón et } \\
\text { al. } 2015 \\
\end{array}$ \\
\hline \multirow{2}{*}{$\begin{array}{l}\text { Bajos sin } \\
\text { salida }\end{array}$} & \multirow{2}{*}{ Caleu Caleu } & \multicolumn{2}{|c|}{ Cerro de los Viejos } & $\begin{array}{l}\text { segunda mitad del } \\
\text { Siglo XIX }\end{array}$ & Serranías & & L-Exr & & - & $\begin{array}{c}\text { seis } \\
\text { represas, } \\
\text { morteros } \\
\text { en la roca }\end{array}$ & $\begin{array}{c}\text { Piana } \\
1979, \\
1981\end{array}$ \\
\hline & & \multicolumn{2}{|c|}{ Médano la Enriqueta } & $\begin{array}{c}1005 \pm 25 \text { UGAMS } \\
4418)\end{array}$ & Médano & $\begin{array}{c}\text { Enterratorio } \\
\text { múltiple }\end{array}$ & L-Exr & $\mathrm{L}$ & $\begin{array}{l}\text { cuentas de } \\
\text { valva con } \\
\text { pigmento } \\
\text { rojo }\end{array}$ & & $\begin{array}{c}\text { Carrera } \\
\text { etal. } \\
2013\end{array}$ \\
\hline
\end{tabular}




\begin{tabular}{|c|c|c|c|c|c|c|c|c|c|c|c|}
\hline \multirow{5}{*}{$\begin{array}{l}\text { Sierras de } \\
\text { Lihue Calel }\end{array}$} & \multirow{9}{*}{ Lihue Calel } & \multirow{5}{*}{ 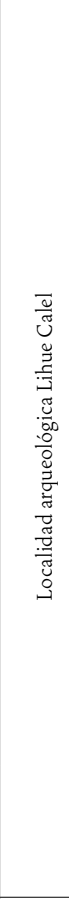 } & Chenque I & $1050-290$ & Sierra & Cementerio & L-Exr & $\mathrm{L}$ & $\begin{array}{c}\text { cuentas } \\
\text { valva, } \\
\text { hueso, } \\
\text { líticas, } \\
\text { minerales } \\
\text { de cobre, } \\
\text { caracoles, } \\
\text { aros de } \\
\text { cobre } \\
\text { nativo, tubo } \\
\text { de cobre } \\
\text { estañifero }\end{array}$ & $\begin{array}{c}\text { rocas } \\
\text { graníticas } \\
\text { demarcando } \\
\text { tumbas }\end{array}$ & $\begin{array}{l}\text { Berón } \\
2004, \\
\text { Berón et } \\
\text { al. } 2007\end{array}$ \\
\hline & & & $\begin{array}{c}\text { Pircados } \\
\text { Valle de La } \\
\text { Estafeta }\end{array}$ & siglo XVIII & Cerro & - & - & - & - & $\begin{array}{c}\text { dos líneas } \\
\text { de pircados } \\
\text { en sentido } \\
\text { O- E hacia } \\
\text { el fondo de } \\
\text { valle } \\
\end{array}$ & $\begin{array}{l}\text { Berón } \\
2004\end{array}$ \\
\hline & & & $\begin{array}{l}\text { Valle del } \\
\text { Dolmen }\end{array}$ & - & Valle & - & - & - & $\begin{array}{l}\text { Pinturas } \\
\text { rupestres }\end{array}$ & - & $\begin{array}{l}\text { Berón } \\
2004\end{array}$ \\
\hline & & & Las Minas & - & $\begin{array}{l}\text { Mina de } \\
\text { cobre }\end{array}$ & - & L-Exr & - & - & - & $\begin{array}{l}\text { Berón } \\
2004\end{array}$ \\
\hline & & & $\begin{array}{l}\text { Alero de las } \\
\text { Pinturas }\end{array}$ & - & Alero & - & L-Exr & - & $\begin{array}{l}\text { Pinturas } \\
\text { rupestres }\end{array}$ & - & $\begin{array}{c}\text { Berón } \\
1997, \\
\text { Molinari } \\
1997\end{array}$ \\
\hline \multirow[t]{4}{*}{$\begin{array}{c}\text { Cuenca del } \\
\text { Curacó }\end{array}$} & & \multirow[t]{2}{*}{ 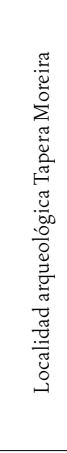 } & $\begin{array}{l}\text { Sitios } 1,2 \\
, 3,4,5\end{array}$ & $\begin{array}{c}\text { Sitio 1: } 360-4590 \\
\quad \pm 60 ; \text { Sitio } 3: \\
\text { 2630 } 060 \text { (BETA } \\
\text { 802558); Sitio } \\
\text { 5:1710-730 }\end{array}$ & $\begin{array}{l}\text { Terrazas } \\
\text { fluviales }\end{array}$ & $\begin{array}{c}\text { Enterratorio } \\
\text { aislado }\end{array}$ & L-Exr & L-Exr & $\begin{array}{c}\text { Cuentas de } \\
\text { Diplodon, } \\
\text { valvas con } \\
\text { ocre, aro } \\
\text { redondo } \\
\text { plano de } \\
\text { cobre nativo } \\
\text { y dos placas } \\
\text { grabadas de } \\
\text { esquisto con } \\
\text { incisiones } \\
\text { finas }\end{array}$ & - & $\begin{array}{l}\text { Berón } \\
2004\end{array}$ \\
\hline & & & La Lomita & $\begin{array}{c}2960 \pm 50(\text { Beta } \\
91934)\end{array}$ & $\begin{array}{l}\text { Terraza } \\
\text { fluvial }\end{array}$ & $\begin{array}{c}\text { Enterratorio } \\
\text { múltiple }\end{array}$ & $\mathrm{L}$ & - & - & - & $\begin{array}{l}\text { Berón } \\
2004\end{array}$ \\
\hline & & \multicolumn{2}{|c|}{ Ponciano Aquito } & sin datos & $\begin{array}{l}\text { Terraza } \\
\text { fluvial } \\
\end{array}$ & - & L-Exr & - & - & - & $\begin{array}{l}\text { Berón } \\
2004\end{array}$ \\
\hline & & \multicolumn{2}{|c|}{ La Terracita } & sin datos & $\begin{array}{l}\text { Terraza } \\
\text { fluvial } \\
\end{array}$ & - & L-Exr & - & - & - & $\begin{array}{l}\text { Berón } \\
2004\end{array}$ \\
\hline \multirow{3}{*}{$\begin{array}{c}\text { Meseta } \\
\text { Basáltica }\end{array}$} & \multirow{5}{*}{ Puelén } & $\begin{array}{r}\text { Esta } \\
s\end{array}$ & $\begin{array}{l}\text { cia Cochicó } \\
\text { os A y B }\end{array}$ & - & Médano & $\begin{array}{c}\text { Enterratorio } \\
\text { aislado }\end{array}$ & L-Exr & $\mathrm{L}$ & - & - & $\begin{array}{c}\text { Berón y } \\
\text { Curtoni } \\
2002\end{array}$ \\
\hline & & Mese & a del Fresco & - & Meseta & - & $\mathrm{L}$ & - & - & - & $\begin{array}{l}\text { Berón } \\
2004\end{array}$ \\
\hline & & Mem & ia del Fresco & - & Meseta & - & $\mathrm{L}$ & - & - & - & $\begin{array}{l}\text { Berón } \\
2004\end{array}$ \\
\hline \multirow[b]{2}{*}{$\begin{array}{l}\text { Casa de } \\
\text { Piedra }\end{array}$} & & Rin & nada Giles & $\begin{array}{c}320 \pm 120(\mathrm{AC} \\
0731), 700 \pm 100 \\
(\mathrm{AC} 0729)\end{array}$ & Médano & - & L-Exr & L-Exr & $\begin{array}{c}\text { tembetá } \\
\text { tipo clavo, } \\
\text { cuentas de } \\
\text { valva }\end{array}$ & - & $\begin{array}{l}\text { Berón } \\
\text { 1991, } \\
\text { Gradín et } \\
\text { al. } 1984\end{array}$ \\
\hline & & \multicolumn{2}{|c|}{$\begin{array}{c}\text { Casa de Piedra sitios } \\
1,2,3,11 \text { y } 12\end{array}$} & $\begin{array}{c}6080 \pm 120 \mathrm{CP} \\
(\mathrm{I}-12.065), 7560 \\
\pm 230(\mathrm{I}-12.159) \\
8620 \pm 190(\mathrm{I}- \\
12.067)\end{array}$ & $\begin{array}{l}\text { Bardas y } \\
\text { terrazas de } \\
\text { ríos }\end{array}$ & $\begin{array}{c}\text { enterratorio } \\
\text { aislado }\end{array}$ & L-Exr & L-Exr & $\begin{array}{c}\text { cuenta de } \\
\text { valva, valva } \\
\text { de caracol } \\
\text { marino } \\
\text { con ocre, } \\
\text { hueso de ave } \\
\text { decorado }\end{array}$ & - & $\begin{array}{l}\text { Gradín et } \\
\text { al. } 1984\end{array}$ \\
\hline
\end{tabular}


Ea. Ana Cecilia y sitios 1 y 5 de la localidad Tapera Moreira en La Pampa, además de sitios en Neuquén, el sur de San Luis y sur de Mendoza (Berón 2004; Berón 1999; Goñi 1986-87; Fernández 1988-1990; Hajduk y Cúneo 19971998; Durán y Ferrari 1991; Salazar Siciliano y Berón 2013; Heider 2015). Ambos tipos coexisten en sitios de los departamentos Malleo y Aluminé de la Provincia del Neuquén, así como en la Localidad Tapera Moreira en La Pampa.

Un tipo particular de evidencia que indica la interacción entre las sociedades de ambos lados de la cordillera, son los aros del tipo "cuadrangular con muesca" y "campaniforme" (Campbell 2004; Berón et al. 2012; Mera et al. 2015). En el Sitio JMC-ol Labranza, cementerio asignado al Período Alfarero Temprano (Complejo Pitrén) fechado en $1.060 \pm 40$ años $\mathrm{AP}$, se recuperó en la tumba 43 , un aro del tipo "campaniforme" que es muy similar al registrado en el entierro 17 del Sitio Chenque I (Tabla 1), cuya cronología es 990 $\pm 60 \mathrm{AP}$, (UGA-02002). Ambos aros son de cobre y no solo muestran una similar composición metalográfica, sino también un similar estilo decorativo y tecnológico. El individuo del entierro 17, a quien estaba asociado el aro, obtuvo valores de $\mathrm{O}^{18}$ de procedencia cordillerana y signos de violencia interpersonal (Berón y Luna 2009; Berón et al. 2013). La cronología radiocarbónica de ambos contextos sugiere la simultaneidad de contactos entre las poblaciones de ambas vertientes cordilleranas (Berón et al. 2012).

\section{^ Los espacios internodales del wall-mapU}

\section{Fronteras y pasos trascordilleranos}

Hacia el oeste de la Pampa Occidental, extensas llanuras $y$ valles precordilleranos formaron parte fundamental de un corredor de transitabilidad que permitía acceder a la multiplicidad de pasos trasandinos, últimos eslabones de interacción con la vertiente occidental de la cordillera (Salazar y Berón 2013). En estas latitudes, los Andes no se comportan como una frontera infranqueable, sino más bien como una unidad geomorfológica inserta en un territorio (Wall-Mapu) que comprende ambas vertientes, además de los valles y relieves montañosos, todo lo cual ofrece un marco biogeográfico favorable para las interacciones y la integración regional, en un largo proceso histórico con regularidades, divergencias y contrastes.
En trabajos previos se ha discutido acerca de la permeabilidad social y cultural de la frontera andina norpatagónica, que se evidencia a través de la cultura material y de los registros bioarqueológicos. Este proceso se manifestó tanto en términos de intercambio de bienes a modo de elementos significativos de integración regional (diacríticos), como también a partir del registro de eventos de conflicto y guerra (Berón 2006; Salazar Siciliano y Berón 2013). La dinámica social de estos espacios condujo paulatinamente a un proceso de integración regional "cuya esencia se encuentra más bien en las prácticas sociales y en los imaginarios, en las relaciones de parentesco y en una multiplicidad de formas", que Bello (2011) califica como formas de "apropiación", pero que nosotros proponemos llamar "formas de integración o de identificación recíproca", dado que en muchos de los casos observados por nosotros o por los cronistas, el proceso no es unilateral sino de mutua apropiación (Bello 2011: 16). En palabras de este autor, "Hay que considerar que tanto los procesos de apropiación (integración) simbólica como material de los territorios conllevan un alto grado de construcción social y cultural" (Bello 2011: 114).

Es así que, según fuentes etnohistóricas, ya desde el siglo XVIII las relaciones de intercambio comercial entre los mapuches del actual territorio chileno y argentino, involucraban a los habitantes indígenas de las pampas y norpatagonia, así como a la población del valle central chileno. Los productos obtenidos en territorios argentinos eran comercializados en los mercados chilenos, conformándose de esta manera relaciones de producción que integraban a ambos lados de la cordillera, con salida al Pacífico, en la etapa previa a la conformación de los Estados-nación (De Jong 2014).

En tiempos prehispánicos los viajeros solitarios o en grupo cruzaban la cordillera por pasos o portezuelos de diferentes características, cuya transitabilidad variaba de acuerdo a las condiciones ambientales. Ya en tiempos ecuestres los viajeros o nampülkafe (en mapundungun) detentaban un prestigio particular en la representación social de los mapuches, según destaca Bello (2011). Un relevamiento de dichos pasos en el área comprendida entre $38^{\circ} 45^{\prime}$ y $40^{\circ} 30^{\prime} \mathrm{S}$ da cuenta de la existencia de por lo menos 33 accesos o sendas de comunicación en la cordillera de este sector (Salazar Siciliano y Berón 2013). 
El control de territorios, accesos y circuitos de los espacios internodales sería además causal de enfrentamientos. Situaciones y procesos de conflicto y de guerras interétnicas acontecidos en el Wall-Mapu han sido relatados en análisis etnohistóricos de los siglos XVIII a XIX (León Solís 1991; Villalobos 1989; Villar y Jiménez 2003) y su correlato arqueológico se ha conservado en el centro de La Pampa, como testigo de estos eventos (Berón 2010, 2014).

Según Bandieri (2013),

...resulta imposible desconocer el hecho de que la cordillera de los Andes sirvió históricamente, $y$ desde las primeras etapas de ocupación indigena, de eje vertebrador de un espacio socialmente integrado, que actuó y sobrevivió por encima de los límites políticosy administrativos impuestos al territorio luego de su conquista militar. No es posible estudiar entonces la historia patagónica atendiendo solamente a sus límites territoriales, sin considerar la importancia de un área de frontera con existencia propia donde se habría conformado, a lo largo del proceso histórico, un espacio social de singulares características, gran dinamismo y alta complejidad (Bandieri 2013: 138).

Estos espacios fronterizos fueron escenarios de nuevas prácticas simbólicas y materiales. En ellos se dieron particulares interacciones sociopolíticas. Estas sociedades indígenas incorporaron la dinámica del cambio, de forma tal que la capacidad de adaptarse y al mismo tiempo resistir a los "otros", se convirtió en una manera diferente de resguardar su autonomía (Nacuzzi y Lucaioli 2014; Zavala Cepeda 2011; Dillehay 2011).

\section{Las rastrilladas (rüpu) o caminos indígenas}

Los espacios internodales en pampa y norpatagonia, aquéllos en los que se desarrollaba la movilidad entre nodos y hacia el Occidente, estaban surcados por rastrilladas (rüpu) o caminos indígenas, que equivalen a lo que en el norte de Chile se consideran redes o caminos viales. Funcionaron como conectores de los nodos principales y secundarios y condujeron de este a oeste y viceversa hacia los pasos cordilleranos (Figura 3). En su recorrido entrelazaban lugares destacados como aguadas, pasturas y sitios de descanso. Pueden pensarse en términos de espacio intermedio en los que se daban tanto conflic- tos como relaciones de intercambio. También eran áreas en las cuales quedaban en suspenso prácticas y formas culturales específicas para experimentar nuevas formas de comunicación con grupos diferentes, solucionar conflictos cotidianos, negociar los intercambios y acordar acciones en común (Nacuzzi y Lucaioli 2014: 52). Aun con opiniones diversas acerca de su trazado y jerarquización entre principales y secundarias, los análisis etnohistóricos coinciden en su importancia para el intercambio primero y para el comercio después, entrelazando nodos que coinciden con sitios arqueológicos de uso recurrente (Berón y Migale 1991a y b).

Curtoni (2007) considera que las rastrilladas constituyen una evidencia arqueológica superficial, en donde quedan plasmados comportamientos sociales, políticos y económicos.

Considerar a los caminos como la causa y consecuencia del traslado y comercio de ganado o como el producto de actividades de subsistencia, constituye una explicación que por un lado, simplifica una situación que era más compleja y por otro lado, homogeniza las causas y variables por las cuales las redes de caminos fueron conformándose. En el área de estudio las rastrilladas registradas presentan diferentes direccionalidades, la mayoría son pequeñas, conectan tolderías, aguadas, bosques, médanos, etc. y en algunos casos evitan determinados lugares posiblemente conceptualizados como tabú simbólicos. Por medio del análisis de reconstrucción de los caminos se observa un ordenamiento espacial relacionado con la localización de los asentamientos en el paisaje $y$ en consecuencia con el sistema de caminos para conectar a los mismos (Curtoni 2007: 12).

Las rastrilladas son huellas formadas por el constante uso, por parte de los grupos humanos que habitaron en la región y del tráfico de animales del siglo XIX (Marini de Díaz Zorita 1979; Mandrini y Ortelli 1992).

Desde el dato etnohistórico podemos citar la narración de Lucio Mansilla acerca de las rastrilladas en territorios del Mamul-Mapu en 1870. Las rastrilladas eran

...surcos paralelos y tortuosos que con sus constantes idas y venidas han dejado los indios en los campos. Estos surcos, parecidos a la huella que hace una carreta la primera vez que cruza por un terreno virgen, suelen ser profundos y constituyen un verdadero 


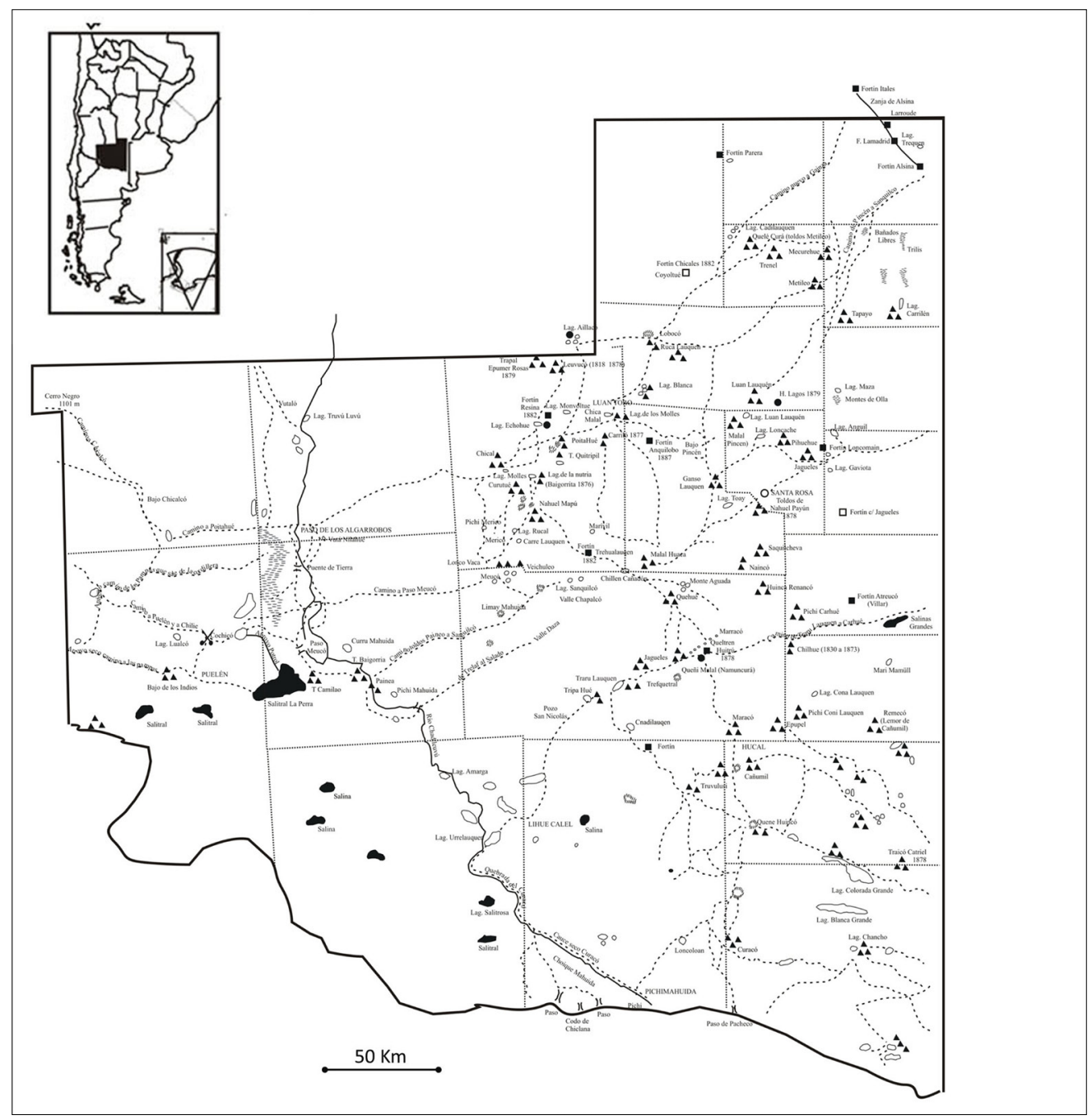

Figura 3. Mapa de las rastrilladas que atravesaban La Pampa en el siglo XIX, modificado de Marini de Díaz Zorita (1979).

camino ancho y sólido. En plena pampa no hay más caminos. Apartarse de ellos un palmo, salirse de la senda, es muchas veces un peligro real; porque no es dificil que ahí mismo, al lado de la rastrillada, haya un guadal en el que se entierran caballo y jinete enteros (Mansilla 2008: 17).

En muchos casos, tanto los caminos como las rutas actuales se han construido sobre las rastrilladas, siguiendo los mismos derroteros que impusieron al paisaje los habitantes primeros de estas tierras. Constituyen un tipo especial de manifestación arqueológica regional, conformando una red de conexiones que definen y preestablecen los sentidos del tránsito y la permeabilidad del paisaje (Curtoni 2007).
Algunos ejemplos etnohistóricos remiten a la continua utilización de estos internodos, a través de los caminos indígenas o "rüpu" por parte de las poblaciones de pampa y norpatagonia (Figura 3):

Salinas Grandes figura como extremo sur de ese camino, que moría o comenzaba en la Guardia de Luján, en los itinerarios de Pinazo, Sizury García, que nos marcan hitos perfectamente identificables en los mapas actuales sin que pueda abrigarse duda alguna sobre su recorrido, pero recordemos ya en 1604, Hernando Arias de Saavedra en su "entrada a los Césares", cubrió, según Stieben, el camino de los chilenos por Luján, Chivilcoy, San Carlos, Carhué, Salinas Grandes, Trurulauquén, 
confluencia del Limay con el Neuquén (Río Negro) y que en 1774, Falkner en su mapa marca un camino que llega hasta Valdivia (Brodsky 1963: 279).

Comprendía pues el Carhué; Guaminí, asiento de Millacurá y su mercado de cautivos, el médano Cahué (el Caquel Huincul de los "parlamentos" y las "saturnales"), las Lomas de Massalle donde Calfucurá inicia sangrientamente su dominio de La Pampa y la laguna Leubuco, empalme de rastrilladas... Efectivamente, se cruzan en Leuvuco: el "camino de García", la rastrillada a Olavarría, la huella que lleva a Nahuel Mapu, y partía sendas para Utracán, Puán, Toay, Mari Mamuel, en un intrincado sistema de comunicaciones de los indios solo conocido y que provocó hasta el momento mismo de la ocupación, serias controversias sobre la exactitud de los mapas que utilizarían las fuerzas expedicionarias en su avance hasta el Río Negro. (Brodsky 1963: 280).

Es posible apreciar a partir de estos datos que durante el siglo XIX, el Wall-Mapu poseía una perfecta articulación de rutas de tránsito que conectaban vados, pasos cordilleranos y rastrilladas. Estos internodos eran utilizados desde tiempos prehispánicos como puntos de descanso, aguadas, pasturas y aprovisionamiento; lugares generalmente controlados por linajes específicos o grupos de alianzas entre diferentes linajes cuando se trataba de territorios vastos o de difícil acceso (Bello 2011).

\section{$*$ Conflicto y espacios internodales}

A partir del análisis de las fuentes etnohistóricas, es posible reconstruir la relevancia y cotidianeidad de las interrelaciones trascordilleranas a través de los espacios internodales. En estas espacialidades las sociedades se entrelazaban y resignificaban sus relaciones en diferentes escalas espaciales y temporales de análisis (Thomas y Knox 1994; Lightfoot y Martínez 1995; Parker 2006). Los espacios de contacto intersocietal del pasado funcionaron como "fronteras dinámicas". Desde el análisis etnohistórico se pueden rastrear esos incesantes y flexibles contactos entre lo que luego serían los territorios de los actuales Estados chileno y argentino. Por ejemplo el alcalde de la ciudad chilena de Concepción, Luis de la Cruz realizó en 1806 un viaje desde el Fuerte de Antuco (región del Biobío) hasta Melincué (Santa Fe). En su derrotero, al pasar por los territorios del Mamul-Mapu relataba en su diario: ...hubo ocasión en que doscientos y más Peguenches que andaban guanaqueando por el lugar de Auquinco (los que se alojaban en la aguada en que nosotros mismos nos hospedamos), de madrugada llegaron allí estos ranquilinos, y acabaron con todos, sin que hubiese quedado uno que lo contase, sino los cuerpos en el campo como bestias, y los rastros de estos nacionales, para conocer que ellos habían sido los del destrozo (De la Cruz 1969: 243-244).

En este relato se observa el constante entrecruzamiento de un sitio a otro de personas que habitaban los territorios de La Pampa central, reorientando sus usos y costumbres según las circunstancias. Las interacciones incluían lazos de parentesco, alianzas políticas, como así también enemistades y enfrentamientos bélicos, los cuales dieron surgimiento incluso a nuevas entidades étnicas.

En otra cita del Viaje de De la Cruz, se evidencia tanto la existencia de reciprocidad transcordillerana, como de conflictos entre las poblaciones de la región de MamulМари (territorio rankulche), y la de los pehuenches en la cordillera de los Andes. Durante la jornada XXVI, del 1 de junio de 1806, que comprende el trayecto desde "el plan de la travesía" hasta Meuco (o Meauco, centrooeste de La Pampa), De la Cruz tuvo una conversación con uno de los caciques principales de los pehuenches en territorio rankulche:

Le pregunté a Manquel:-¿Qué cómo tiene en estas tierras tantos tiempos, y desde qué tiempo? ¿Qué si siempre han sido estas tierras pobladas de indios, o fueron sólo pobladas cuando se vinieron los ranquelinos de la cordillera a habitarlas?... "Que en estos terrenos habitan indios desde tiempos inmemoriales, que así oyó a sus antepasados, y siempre estas naciones fueron enemigas de los otros Guilliches, que hoy gobierna Canigcolo. Que Quiñeipil fue gobernador Pehuenche, y tan guerrero que siempre estuvo con la lanza en las manos, maloqueando a los guilliches y llamistas, $y$ aún a estos. Que encolerizadas estas tres naciones se comunicaban las lunas en que los habian de asaltar, y así a un mismo tiempo y a una misma hora, los entraban por diferentes partes, $y$ los fueron destruyendo" (De la Cruz 1969: 243).

En este relato se otorga una identidad étnica a quienes fueron las víctimas y victimarios, como corolario de un largo período (inicios del siglo XIX) de relaciones entre los pehuenches y sus vecinos los rankulches. Sin embargo los espacios internodales han sido testigos de conflictos de diverso tipo desde tiempos prehispánicos. 
Así lo atestigua el registro bioarqueológico del cementerio Sitio Chenque I en la Localidad Lihué Calel. En él se recuperaron entierros múltiples con diversas señales de violencia, entre ellas una importante cantidad de puntas de proyectil insertas en diferentes partes anatómicas. Dos de estos entierros múltiples, el Entierro 29 y el Conjunto 21/23, son eventos sincrónicos de muerte, con cronologías similares.

El conjunto 21/23 presenta un MNI de cinco individuos adultos maduros y su cronología es de $320 \pm 30$ años AP. Los cuerpos fueron inhumados como entierros secundarios, con la variante disposición, que implica la presencia de partes esqueletarias articuladas (columnas vertebrales, miembros superiores e inferiores). El número de puntas de proyectil insertas en piezas óseas es de cinco. Estaban alojadas en diferentes porciones anatómicas de por lo menos tres individuos (costilla, vértebras lumbares y vértebras cervicales). La estructura de inhumación no presenta indicios de preparación previa, sino que remite a un hoyo cónico practicado azarosamente para contener el conjunto óseo, sin ningún ordenamiento.

Entierro 29, que presenta un MNI de 17 individuos, y una cronología de $390 \pm 30$ años AP. La mayoría de los individuos son jóvenes de entre 16 y 19 años de edad. Los cuerpos también fueron inhumados como entierros secundarios, con la variante disposición. La cantidad de puntas de proyectil recuperadas es de 42 , de las cuales 28 estaban insertas en diversas piezas óseas (vértebras dorsales, lumbares y cervicales, omóplato, clavícula, costillas, esternón, zona pubisacetábulo, fémur, tibia, peroné, entre otros), nueve se hallaban asociadas (probablemente quedaron insertas en los tejidos) y cinco presentes en los sedimentos circundantes. A diferencia del caso anterior, la estructura de inhumación presenta claros indicios de preparación previa, ordenamiento interno y límites bien definidos. Los restos esqueletarios se encuentran acomodados y superpuestos en una estructura monticular subcircular de 1,20 m de largo por $0,80 \mathrm{~m}$ de ancho aproximadamente. Hay partes esqueletarias completamente articuladas, aunque seccionadas en la zona articular de las porciones óseas contiguas, en particular columnas vertebrales y miembros superiores e inferiores (antebrazos, manos; pantorrillas y pies). Por otra parte, una gran cantidad de huesos de las extremidades in- feriores fueron agrupados y alineados en un sector de la estructura. Otras piezas óseas fueron acomodadas cuidadosamente, guardando un patrón recurrente que asocia cráneos con huesos planos a sus costados, especialmente coxales, todos ellos en los bordes externos de la estructura de entierro.

Los individuos del Entierro 29 fueron inhumados en un espacio previamente preparado y los restos acomodados y ordenados con ciertos patrones preestablecidos, sugiriendo algún tipo de ceremonia o ritual. Por el contrario, los individuos del conjunto $21 / 23$ fueron inhumados desordenadamente en un pozo cónico (de o,80 m de profundidad aproximadamente), en el cual los elementos óseos y las partes anatómicas aparecen desordenados y dispersos. El hoyo fue cubierto con rocas. Esto sugiere que los restos óseos podrían haber sido arrojados allí, sin mediar ninguna ceremonia o ritual, a diferencia del cuidadoso acomodamiento de las partes esqueletarias del Entierro 29 antes descripto.

El conjunto 21/23 habría sido un evento más acotado respecto al sector de la población involucrado, de tipo venganza o raid, equivalente a la venganza o tautulun según Boccara (2009), mientras que el Entierro 29 podría corresponder a una guerra planificada, asimilable a la guerra propiamente dicha o weichan según Boccara (2009). En este sentido Aranda Jiménez y Sánchez Romero (2005) postulan que la aparición de la guerra va de la mano de cambios demográficos, reconfiguraciones sociales y probablemente disputas territoriales como las descriptas en las fuentes históricas (Berón 2014).

\section{* Discusión y consideraciones finales}

A partir del análisis del registro arqueológico y de fuentes etnohistóricas pampeanas, se abordaron cuestiones vinculadas a fenómenos de interacción y conflicto en parte de los territorios del Wall-Mapu. El enfoque propuesto adquiere importancia en el marco de una aproximación teórica que tiene en cuenta los espacios de interacción, los nodos, los recursos asociados a ellos y las prácticas sociales involucradas.

La macrorregión considerada es heterogénea y comprende varios ecosistemas: estepa herbácea, estepa arbustiva, monte xerófilo, estepa patagónica y bosques andino-patagónicos considerando también la región de la Araucanía. 
Este complejo panorama ambiental más los usos y transformaciones sociales del mismo, dieron lugar al sistema de interacción, intercambio, complementariedad social y dinámica poblacional (sensu Berón 2006) que se refleja en el registro arqueológico del área de investigación.

El análisis del conjunto de evidencias arqueológicas encontradas en distintos puntos del paisaje pampeano, respaldan una propuesta de interacción e integración regional. La implementación de diversas líneas de investigación, entre las que se contemplan los estudios bioarqueológicos, arqueobotánicos, de análisis cerámico, isotópicos, de procedencia de recursos líticos y de fuentes documentales han proporcionado resultados confluyentes hacia la caracterización de al menos dos grupos poblacionales de diversa procedencia. Para establecer la procedencia geográfica de los individuos, se desarrollaron estudios isotópicos de di8O en 10 entierros. Los resultados nos permiten diferenciar a los individuos locales de aquellos extrarregionales enterrados en el cementerio de Lihue Calel. Dos individuos (Entierros 17 y 19) presentan valores di 80 empobrecidos (-8.1 y $-8.3 \%$ ), lo que significa una procedencia andina. Además, ambos se ubican en el primer período de uso del cementerio. Los restantes ocho individuos con valores de $\mathrm{d} 18 \mathrm{O}$ entre $-4 \%$ a $-1,7 \%$ o corresponden al rango isotópico local (Berón et al., 2013). La identificación de personas extralocales enterradas en dicho cementerio es una evidencia importante de la movilidad y la interacción en una gran escala espacial.

Ambas poblaciones convergen en el uso efectivo de algunos nodos principales o localidades arqueológicas como la Localidad Lihue Calel, Localidad San Sixto y la Localidad Tapera Moreira, así como de los espacios internodales respectivos. La propuesta ha sido entretejer el pasado prehispánico con el relato construido en las crónicas, asumiendo que tanto rastrilladas como pasos intermontanos estuvieron en funcionamiento durante, al menos, los últimos 2 mil años. Este planteo comprende tanto aquellos grupos sociales de la Pampa Occidental como los de ambas vertientes de la región surandina que forman parte del corredor bioceánico (sur de Cuyo, noroeste de Neuquén, norte de Río Negro, región de La Araucanía, región de Los Lagos y posiblemente Chile central).

Retomando la concepción cosmológica del pueblo mapuche respecto a la idea del espacio-territorio, la conforma- ción del mapu (tierra) tiene una doble dimensión; por una parte, está el plano espacial que posee una connotación inmaterial, intangible, no física para definir los diferentes espacios o visiones del mundo, denominado Waj-Mapu o Wall-Mapu, en donde el che (gente) se conecta con la creación, marcando la espiritualidad de la sociedad mapuche, y por otra parte, este Waj-Mapu también se refiere al plano material (Informe de la Comisión Verdad Histórica y Nuevo Trato 2003).

Considerando este último plano del Wall-Mapu, y en particular su materialidad, es preciso señalar un conjunto de ítems, enumerados en la Tabla 1, que corroboran la importancia del intercambio y circulación de bienes a larga distancia como estrategia de integración regional:

1. Presencia de adornos de metal con diseños extrarregionales y diferentes técnicas de manufactura. Tupus de plata y de latón recuperados en diferentes áreas arqueológicas y tres tipos de morfologías de aros de cobre nativo (campanifome, redondo plano y espiralado). Las técnicas de manufactura incluyen el martillado y la técnica de la cera perdida. También se recuperaron otros adornos personales como elementos tubulares metálicos de cobre-estañífero, lo que implica el uso de nuevas técnicas del trabajo de metales y la obtención de otras materias primas como el estaño para lograr esta aleación.

2. Otros adornos personales como cuentas de collar fueron confeccionados con materias primas extrarregionales como turquesa, caracoles y valvas de la costa atlántica. Un ítem de particular interés es el registro de tembetás en distintos sectores de la Provincia de La Pampa. Dichos adornos son muy frecuentes en el nordeste argentino, pero también se los encuentra con cierta frecuencia en algunos sitios de Chile central y de norpatagonia, desde la cordillera hasta la costa (Fernández 1988-1990).

3. Dentro de las materias primas líticas se destaca el uso de obsidiana. Hasta el momento se analizaron 18 muestras que plantean procedencias de fuentes cordilleranas: La Bandera y lago Lolog en Neuquén; Paso Pehuenche y Las Cargas/Paramillos al sur de Mendoza (Giesso et al. 2008, López et al. 2009). 
4. Presencia de cerámica del tipo challas, complejo rojo sobre blanco y rojo engobado. En el caso particular de las ollas tipo challas, se identificaron en sus residuos de uso, granos de almidón de maíz (Zea mays). Este último no era cultivado localmente sino obtenido por vía del intercambio (Musaubach y Berón 2012, 2016).

A partir de estos procesos, diferentes trayectorias sociales transformaron lugares en paisajes sociales (nodosinternodos). La culturización del espacio puede formar parte y ser la expresión de un proceso de socialización del espacio a través del tiempo (Curtoni y Berón 2011). La misma se manifiesta, se objetiva y/o materializa a través de las vías de tránsito (rastrilladas, pasos cordilleranos), las marcas (arte rupestre) y los monumentos (represas, miradores, montículos) dispuestos en el espacio. El Valle de las Pinturas en la Localidad Lihue Calel es un claro ejemplo donde discutir el proceso por el cual, grupos de cazadores recolectores conformaron un paisaje cultural en torno a un espacio sagrado, cuya ordenación diferencial es el reflejo de una acumulación de acciones y sentidos individuales y grupales a través del tiempo. En este valle se combina la localización de pinturas rupestres, arquitectura monumental y un cementerio prehispánico, en relación a rasgos topográficos y culturales del paisaje (Berón y Curtoni 2012).

En trabajos anteriores se ha señalado que este extenso territorio fue explorado y colonizado por grupos de aborígenes de diferentes parcialidades étnicas y políticas desde hace varios milenios. Estos transitados territorios reconocían el paso de etnias que sin duda se fueron "mixturando", entremezclando, como parte del estratégico juego de las alianzas. La puja por los espacios fronterizos en los cuales se dirimía el manejo del intercambio y el comercio con transcordillera, dio lugar al surgimiento de conflictos y enfrentamientos, que también han quedado plasmados en el registro arqueológico. Sin embargo, la existencia de tales redes resultó de gran importancia al momento de requerir la colaboración de los aliados o el cobijo en el territorio vecino, cuando las huestes colonizadoras europeas avanzaron sobre el territorio indígena.

Las tierras del Mamül-Mapu fueron testigo de un flujo y reflujo de pueblos originarios, cuando a finales del siglo XIX el expansionismo nacional desestructuró la exitosa estrategia de articulación regional indígena. La intrincada trama de redes, que visualizamos en las rastrilladas, se destejió hasta casi desaparecer. La mayor parte de las poblaciones originarias fueron cercenadas, mientras que algunos grupos se vieron reducidos a tierras marginales. Otros prefirieron ocultar su adscripción indígena para sobrevivir (Berón 2013b). En este enfoque se destaca el surgimiento y desarrollo de diferentes mecanismos de integración regional, que dieron origen a procesos de interacción multiétnica a escala macrorregional, las cuales dieron lugar también a procesos de etnogénesis.

Un elemento fundamental que influyó en la integración multiétnica como a la relación entre los pueblos originarios con los "huinca" o blancos, en el contexto de la utilización de los espacios internodales analizados, fue la introducción del caballo entre los siglos XVIII y XIX. La adopción de los hábitos ecuestres, junto con la introducción -más tardía- de vacunos y ovinos modificó algunos aspectos del modo de vida en todo el territorio del Wall-Mapu, ya que "el caballo tuvo una amplia aceptación tanto entre los mapuches cultivadores en Chile como entre los cazadores pampeanos; ambos pueblos adquirieron algunos rasgos comunes que tendieron a acortar las amplias diferencias que los separaban" (Mandrini 1987: 314). La adopción del caballo agilizó la capacidad de movimiento a grandes distancias de las poblaciones del Wall-Mapu, todo lo cual incrementó la utilización y demarcación de las rastrilladas, dada la velocidad y capacidad de carga que permitía este cuadrúpedo, generando una mayor asiduidad de contactos interétnicos y expandiendo los circuitos comerciales (Mandrini 1987).

La propuesta general de este trabajo es que durante el Holoceno Tardío (últimos 2 mil años) se generó un corredor de interacción entre grupos cazadores-recolectores de la zona central del país, alcanzando sectores transcordilleranos. Este flujo de relaciones sociales enfatizó fuertemente el vector este-oeste en sus movimientos, generando un entramado social que incluía relaciones fluidas y cambiantes que se manifestaron tanto en la forma de alianzas sociales y parentales, como de conflictos y situaciones de violencia. A su vez, la información generada a través de la etnohistoria y de testimonios etnográficos, que han sido sistematizados en este trabajo, contribuyeron a ajustar las interpretaciones obtenidas a través del registro material. 
Agradecimientos Las investigaciones se realizaron en el marco de los proyectos PICT 0437-2011, PIP o834 y UBACYT-F540. Agradecemos al Dr. Manuel Carrera Aizpitarte, quien colaboró en la confección de la Figura 3, y al ilustrador Jorge González, que confeccionó las Figuras 1 y 2. También a los Dres. Pimentel y Berenguer por la posibilidad de participar en el simposio que dio origen a este trabajo.

\section{$*$ Referencias citadas}

ADÁN, L., C. GARCÍA, R. MERA, M. GODOY, D. CARABIAS y D. MUNITA. 2010. Ms. Habitando bosques, lagos y volcanes: comparación de las ocupaciones arcaica y alfarera temprana en los ámbitos cordilleranos Llaima-Lonquimay y Villarrica- Lanín $\left(39^{\circ} \mathrm{S}\right)$. Informe Final Proyecto FONDECYT 1060216, Santiago de Chile.

ADÁN, L., R. MERA, M. URIBE y M. ALVARADO. 2005. La tradición cerámica bícroma rojo sobre blanco en la región sur de Chile: los estilos decorativos Valdivia y Vergel. Actas del XVI Congreso Nacional de Arqueología Chilena, pp. 399-410. Tomé.

ARANDA JIMÉNEZ, G. y M. SÁNCHEZ ROMERO. 2005. The origin of warfare: later prehistory in southeastern Iberia. En Warfare, Violence and Slavery in Prehistory, M. Parker Pearson e I. J. Thorpe (Eds.), pp. 181-194. BAR International Series Archaeopress, Oxford.

BAHAMONDES, F. e I. CORREA. 2008. Ms. Alfarería de tierras altas: Informe de análisis cerámico Aleros Cabeza de Indio-1, Purranque 1-2-3 y Colico-1. Informe de Avance Proyecto FONDECYT 1060216 - Año 2, L. Adán (Comp.), Santiago de Chile.

BAHAMONDES, G. Mapa del Wall-Mapu. http://pueblosoriginariosarcherymuseum.blogspot.com.ar/2012/10/7-al-10-deoctubre-20-aniversario-de-la.html (acceso febrero 2016).

BANDIERI, S. 2005. Cruzando la cordillera... La frontera argentino-chilena como espacio social. Centro de Estudios de Historia Regional. CEHIR. Facultad de Humanidades. Universidad Nacional del Comahue, República Argentina.

BANDIERI, S. 2013. Cuando las fronteras fueron límites: el incremento de la penetración estatal en la Patagonia argentina. En Araucanía-Norpatagonia: la territorialidad en debate. Perspectivas ambientales, culturales, sociales, politicas y económicas, M. Nicoletti y P. Núñez (Comps.), pp. 137-149. Instituto de Investigaciones en Diversidad Cultural y Procesos de Cambio. Universidad Nacional de Río Negro, Bariloche.

BARTOLOMÉ, M. A. 2003. Los pobladores del "Desierto": genocidio, etnocidio y etnogénesis en la Argentina. En Cuadernos de Antropología Social 17: 162-189. FFyL-UBA, Buenos Aires.

BELLO, A. 2011. Nampülkafe: El viaje de los Mapuches de la Araucanía a las pampas argentinas. Ediciones Universidad Católica de Temuco, Temuco.
BERENGUER, J. 2004. Tráfico de Caravanas, Interacción Interregional y Cambio en el Desierto de Atacama. Ediciones Sirawi, Santiago de Chile.

BERENGER, J. y G. Pimentel. 2010. Presentación. Simposio Arqueología de los espacios vacíos: Una aproximación internodal a las relaciones intersocietales. Actas del XVII Congreso Nacional de Arqueología Chilena, pp. 1305-1308. Ediciones Kultrún, Valdivia.

BERÓN, M. 1991. Las ocupaciones tardías del Área Casa de Piedra, Pcias. de La Pampa y Río Negro. Runa XIX: 95-115 (1989-90), Buenos Aires.

BERÓN, M. 1997. Puesta en valor de recursos culturales. La arqueología del Parque Nacional Lihué Calel y la recuperación del pasado. Precirculados de las Jornadas de Investigación y Conservación en el Parque Nacional Lihué Calel, p. 6. Administración de Parques Nacionales. Secretaría de Recursos Naturales y Desarrollo Sustentable. Presidencia de la Nación. 10 y 11 de julio de 1997. Santa Rosa, La Pampa.

BERÓN, M. 1999. Contacto, intercambio, relaciones interétnicas e implicancias arqueológicas. Soplando en el viento... Actas de las Terceras Jornadas de Arqueología de la Patagonia, pp. 287-302. Neuquén.

BERÓN, M. 2004. Dinámica poblacional y estrategias de subsistencia de poblaciones prehispánicas de la cuenca Atuel-Salado-ChadileuvúCuracó, Provincia de La Pampa. Tesis Doctoral no publicada, FFyLUBA, Buenos Aires.

BERÓN, M. 2005. Circuitos prehispánicos de movilidad e interacción social en el centro- sur argentino chileno. En Encuentro Itinerarios y rutas culturales. Centro Internacional para la Conservación del Patrimonio (CICOP) y Comisión Nacional de la Manzana de las Luces, Buenos Aires.

BERÓN, M. 2006. Relaciones interétnicas e identidad social en el registro arqueológico. En Género y Etnicidad en la Arqueología Sudamericana, Serie Teórica núm. 4, vol. I. Williams y B. Alberti (Eds.), pp. 119-138. FACSO, UNICEN, Olavarría.

BERÓN, M. 2007a. Circulación de bienes como indicador de interacción entre las poblaciones de la pampa occidental y sus vecinos. En Arqueología en las Pampas, C. Bayón, A. Pupio, M. I. González, N. Flegenheimer y M. Frére (Eds.), pp. 345-364. So- 
ciedad Argentina de Antropología. ISBN 978-987-1280-06-3, Buenos Aires.

BERÓN, M. 2007b. Integración de evidencias para evaluar dinámica y circulación de poblaciones en las fronteras del Río Colorado. En Arqueología de Fuego-Patagonia. Levantando piedras, desenterrando huesos... y develando arcanos, F. Morello, M. Martinic, A. Prieto y G. Bahamonde (Eds.), pp: 173-188. Ediciones CEQUA, Punta Arenas, Chile.

BERÓN, M. 2010. Circuitos regionales y conflictos intergrupales prehispánicos. Evidencias arqueológicas de violencia y guerra en la pampa occidental Argentina. Actas del XVII Congreso Nacional de Arqueología Chilena, Tomo I, pp. 493-503. Sociedad Chilena de Arqueología, Universidad Austral de Chile. Ediciones Kultrún, Valdivia.

BERÓN, M. 2013a. El rehue de Ñorquinco, un diacrítico de interacción social y cultural trasandino. En Araucanía-norpatagonia, la territorialidad en debate: perspectivas ambientales, culturales, sociales, politicas y económicas, M. A. Nicoletti y P. G. Núñez (Eds.), San Carlos de Bariloche.

BERÓN, M. 2013b. La arqueología del sector occidental de la región pampeana. Trayectoria y reposicionamiento respecto a la arqueología nacional. Revista del Museo de Ciencias Naturales de La Plata, SecciónAntropología 13(87): 1-25. ISSN 0376-4638. La Plata.

BERÓN, M. 2014. Patrones de violencia en sociedades preestatales: tipificación de eventos a partir de diferentes casos entre cazadores-recolectores de la Pampa Occidental Argentina. Una propuesta. En Indicadores arqueológicos de violencia, guerra y conflicto en Sudamérica, J. López Mazz y M. Berón (Eds.), pp. 81-116. Comisión Sectorial de Investigación Científica/Universidad de la República. Subcomisión de Apoyo a Publicaciones de la CSIC, Montevideo, Uruguay.

BERÓN M. 2015. Chronological distribution and disturbance factors to evaluate population dynamics in Western Pampas, Argentina. Quaternary International 356: 74-88. Special Issue Volume "Paleodemography in South America", C. Mendez Melgar y L. Prates (Eds.).

BERÓN, M. 2016. Dunes, hills, waterholes, and saltpeter beds: attractors for human populations in Western Pampa, Argentina. Quaternary International. Online publication complete: 25-JUL2016 DOI information: 10.1016/j.quaint.2016.03.001.

BERÓN, M. y L. MIGALE, 1991a. Rutas de comercio indígena y paraderos: el sitio Tapera Moreira, Pcia. de La Pampa. Shincal 3(3): 129-134. Catamarca.
BERÓN, M. y L. MIGALE. 1991b. Control de recursos y movilidad en el sur pampeano. En Boletín del Centro núm. 2, pp. 40-50. Centro de Registro Arqueológico y Paleontológico de la Dirección de Museos y Sitios Históricos de la Subsecretaría de Cultura de la Provincia de Buenos Aires, La Plata.

BERÓN, M. y R. CURTONI. 2002. Atlas arqueológico de la provincia de La Pampa. Serie Monográfica núm. 2. INCUAPA. Facultad de Ciencias Sociales, UNICEN. 144 pp.

BERÓN, M., C. ARANDAy L. LUNA. 2007. Variabilidad y tendencias temporales de las prácticas mortuorias en el Sitio Chenque I. En Tras las huellas de la materialidad. Resúmenes ampliados del XVI Congreso Nacional de Arqueología Argentina, pp. 247-253. Facultad de Humanidades y Ciencias Sociales. Universidad Nacional de Jujuy, San Salvador de Jujuy.

BERÓN, M. y L. LUNA. 2009. Distribución espacial y cronológica de la deformación craneana tabular erecta en Pampa y Norpatagonia. En Arqueología de la Patagonia. Una mirada desde el último confín, F. Santiago, M. Salemme, M. Álvarez, E. Piana, M. Vázquez y M. E. Mansur (Comps.), pp. 561-575. Utopías, Ushuaia.

BERÓN, M., R. MERAy D. MUNITA. 2012. Traspasando barreras, interacciones sociales y conflicto allende la cordillera andina. $A c$ tas del XVIII Congreso Nacional de Arqueología Chilena, pp. 351-357. Sociedad Chilena de Arqueología, Santiago de Chile.

BERÓN, M.y R. CURTONI. 2012. Identidad y territorialidad en un paisaje ritualizado. Las sierras de Lihué Calel, La Pampa, Argentina. En Paisajes culturales: memorias de las Jornadas de reflexión acerca de los paisajes culturales de Argentina y Chile, en especial los situados en la región Patagónica, Río Gallegos, 13 al 15 de junio de 2012, V. Navarro y S. Espinosa (Comps. de la primera edición), pp. 181196. Universidad Nacional de la Patagonia Austral, 2012. CDROM. ISBN 978-987-1242-71-9.CDD 363.69. Río Gallegos.

BERÓN, M., L. LUNAy R. BARBERENA. 2013. Isótopos de oxígeno en restos humanos del sitio Chenque I: primeros resultados sobre procedencia geográfica de individuos. En Tendencias Teórico-metodológicas y Casos de Estudio en la Arqueología de Patagonia, A. F. Zangrando, R. Barberena, A. Gil, G. Neme, M. Giardina, L. Luna, C. Otaola, S. Paulides, L. Salgán y A. Tivoli (Eds.), pp. 27-38. Altuna Editores. Museo de Historia Natural, San Rafael, Mendoza.

BERÓN, M., M. CARRERA AIZPITARTE y F. PÁEZ. 2015. Arqueología en el área de Valles Transversales (provincia de La Pampa, Argentina). Caracterización y tendencias de los conjuntos arqueológicos. Implicancias sociales en la construcción del paisaje. Relaciones de la Sociedad Argentina de Antropología, tomo XL(2): 549-587. 
BOCCARA, G. 2009. Los vencedores. Historia del pueblo mapuche en la época colonial. Quillqa-Universidad Católica del Norte, San Pedro de Atacama.

BRODSKY, L. 1963. Estado actual de la rastrillada de los chilenos en Cahue. En I congreso del Área Araucana, tomo II, Provincia del Neuquén y Junta de Estudios Araucanos (Eds.), pp. 279-282. Buenos Aires.

BULLOCK, D. 1970. La cultura Kofkeche. Boletín de la Sociedad de Biología de Concepción, vol. XLIII.

CÁCERES, I., C. WESTFALL, L. CONTRERAS, M. SAAVEDRA, C. BELMAR y H. VELÁSQUEZ. 2005. Asentamientos Indígenas en el Alto Bio-Bío. Actas del XVI Congreso Nacional de Arqueología Chilena, pp. 293-304. Tomé.

CAMPBELL, R. 2004. El trabajo de metales en la Araucanía (siglos XXVII d.C.). Memoria para optar al título de Arqueólogo. Universidad de Chile. Facultad de Ciencias Sociales. Escuela de Ciencias Sociales. Departamento de Antropología. www.academia. $\mathrm{edu} / 1590738$.

CANUHÉ, G. 1998. Un largo camino de regreso a casa. Reseña histórica de la nación mamülche, pueblo rankül (ranquel), habitante desde siempre del centro de la actual Argentina. Mimeo.

CARRERA AIZPITARTE, M., L. LUNA, C. ARANDA y M. BERÓN. 2013. Médano La Enriqueta: un lugar de entierro de cazadores tardíos sobre el río Colorado (Dpto. Caleu Caleu, provincia de La Pampa). Revista del Museo de La Plata, Universidad Nacional de La Plata, Buenos Aires.

CASAMIQUELA, R. 1965. Rectificaciones y ratificaciones. Hacia una interpretación definitiva del panorama etnológico de la Patagonia y área septentrional adyacente. Cuadernos del Sur. Bahía Blanca, Universidad Nacional del Sur.

CASAMIQUELA, R. 1969. Un nuevo panorama etnológico del área panpampeana y patagónica adyacente. Pruebas Etnohistóricas de la filiación tehuelche septentrional de los Querandies. Museo Nacional de Historia Natural, Santiago de Chile.

CASAMIQUELA, R. 1985. Bosquejo de una etnología de la provincia de Río Negro. Viedma, Fundación Ameghino.

CONSEJO NACIONAL DE LA CULTURA Y LAS ARTES. 2012. Conociendo la cultura Mapuche. El Consejo, ISBN 9789563520309 , Santiago de Chile.

COORDINADORA DE ORGANIZACIONES MAPUCHE DE NEUQUÉN-PUELMAPU. 2001. Derecho Mapuce - NOR FE-
LEAL, El Concepto de Territorio. M/S, Neuquén. www.mapuche.info/mapuint/puelmapuo10425.html (acceso 15.02.2011).

CRIVELLI, E. 2008 Comparación de conjuntos cerámicos de la cuenca del río Limay: bosque y estepa, tumbas y campamentos. En Tras la senda de los ancestros: Arqueología de Patagonia, P. Azar, E. Cúneo y S. Rodríguez (Eds.), San Carlos de Bariloche.

CURTONI, R. 2007. Arqueología y paisaje en el área centro-este de La Pampa. Tesis Doctoral inédita. Facultad de Ciencias Naturales y Museo, Universidad Nacional de La Plata.

CURTONI, R. y M. BERÓN. 2011. Perception, identity and sense in the social and ritual building of landscape. Revista Chilena de Antropología 24: 97-118. Facultad de Ciencias Sociales. Universidad de Chile. A. Troncoso (Ed.), ISSN 0716-3312. Santiago de Chile.

DE JONG, I. 2014. El negocio de la paz: la política diplomática de Calfucurá durante la organización nacional (1862-1873). En Pueblos indígenas, Estados nacionales y fronteras. H. Trinchero, L. Campos Muñoz y S. Valverde (Coords.). FFyL-UBA, Buenos Aires.

DE LA CRUZ, L. 1969 [1835]. Viaje de Don Luis de la Cruz desde el Fuerte el Ballenar hasta la ciudad de Buenos Aires. En Colección de Obras y Documentos Inéditos Relativos a la Historia Antigua y Moderna de las Provincias del Río de La Plata 1, P. de Angelis (Ed.), pp. 119-310. Lajouane, Buenos Aires.

DIANA, A., A. FERNÁNDEZ, G. GONZÁLEZ y E. LUCERO. 2014. Muerto sobre muerto: análisis preliminar de un entierro hallado en contexto de rescate (La Tranquera, Colonia San Sixto, La Pampa). Póster y resumen presentados en el VII Congreso de Arqueología de la Región Pampeana Argentina, Rosario.

DILLEHAY, T. 2011. Monumentos, Imperios y Resistencia en los Andes. El sistema de gobierno mapuche y las narrativas rituales. Qillqa. Universidad Católica del Norte, región de Antofagasta, Chile.

DILLEHAY, T. 2002. Una historia incompleta y una identidad cultural sesgada de los mapuches. En Colonización, resistencia y mestizaje en las América (Siglos XVI-XX). G. Boccara (Ed.), pp. 163-184. Ediciones Abya-Yala. Quito, Ecuador.

DONOSO, S. y M. J. Gallego. 2010. Ms. Análisis cerámico sitios del ámbito cordillerano, eje Lonquimay Llaima: Alero Cautín-1, Pichipehuenco-2 y Carilafquen-1. Informe Final Proyecto FONDECYT 1060216, L. Adán (Comp.), Santiago.

DOS SANTOS MONTANGIE, A. 2014. Ni los historiadores ni nadie lo tiene en cuenta y, sin embargo, mi abuela me lo contaba... Narrativas históricas de los ranqueles de La Pampa. RUNA 35(2): 89-104. 
DURÁN, V., M. GIESSO, M. D. GLASCOCK, G. NEME, A. GIL y L. SANHUEZA R. 2004. Estudio de fuentes de aprovisionamiento y redes de distribución de obsidiana durante el Holoceno Tardío en el sur de Mendoza (Argentina). Estudios Atacameños. Arqueología y antropología surandinas 28: 25-43.

DURÁN, V. y J. FERRARI. 1991. El proceso de araucanización del sur mendocino desde una perspectiva arqueológica. Actas del XI Congreso Nacional de Arqueología Chilena 3: 165-188.

ERIZE, E. 1987. Mapuche 1. Editorial Yepun, Buenos Aires.

FALABELLA, F., L. SANHUEZA, G. NEME y H. LAGIGLIA. 2001. Análisis comparativo de cerámica Aconcagua entre Chile y Argentina. Relaciones de la Sociedad Argentina de Antropología XXVI: 193-214.

FERNÁNDEZ, J. 1988-1990. La Cueva de Haichol, Arqueología de los pinares cordilleranos del Neuquén. En Anales de Arqueología y Etnología, vol. I, Universidad Nacional de Cuyo, FFyL, Mendoza.

GIESSO, M., M. A. BERÓN y M. D. GLASCOCK. 2008. Obsidian in Western Pampas, Argentina: Source Characterization and Provisioning Strategies. International Association for Obsidian Studies Bulletin 38: 15-18.

GOÑI, R. A. 1986-1987. Arqueología de sitios tardíos en el valle del río Malleo, provincia del Neuquén. Relaciones de la Sociedad Argentina de Antropología XVIII/1, NS: 37-66.

GORDON, A. 1991. La Casa Fuerte Santa Sylvia. Excavación de Sondeo. Actas del XI Congreso Nacional de Arqueología Chilena, tomo III. Museo Nacional de Historia Natural. Sociedad Chilena de Arqueología, Santiago.

GRADÍN, C., C. VAYA, M. QUINTANA, H. NAMI, A. SALVINO, M. BERÓN, A. AGUERRE. 1984. Investigaciones arqueológicas en Casa de Piedra. Dirección General de Cultura y Ente Ejecutivo Casa de Piedra, 149 pp. Pcia. de La Pampa.

HAJDUK, A. 1986. Arqueología de Montículo Angostura. Primer fechado radiocarbónico, Provincia del Neuquén. Arqueología, 1, Museo Histórico Provincial, Neuquén.

HAJDUK, A., A. M. ALBORNOZ y M. LEZCANO. 2011. Espacio, cultura y tiempo: el corredor bioceánico norpatagónico desde la perspectiva arqueológica. En Cultura y Espacio. Araucanía-Norpatagonia, P. Navarro Floria y W. Delrio (Comps.), pp. 262-287. IID y PCa - Universidad Nacional de Río Negro.

HAJDUK, A. y E. M. CÚNEO. 1997-1998. Rescate arqueológico en San Martín de los Andes (departamento Lácar, provincia del Neuquén) y algunas reflexiones acerca de la cerámica con decoración valdiviana. Relaciones de la Sociedad Argentina de Antropología XXII-XXIII: 319-342.
HEIDER, G. 2015. Los Pueblos originarios en el norte de Pampa Seca. Una mirada arqueológica a los cazadores-recolectores del sur de las provincias de Córdoba y San Luis, Argentina. Tesis Doctoral inédita. Universidad Nacional de Córdoba, Argentina.

INFORME DE LA COMISIÓN VERDAD HISTÓRICA Y NUEVO TRATO. 2003. Comisión de Trabajo Autónomo Mapuche Mapu Küpal Azkunun Zugu. Fundamentos y Manifestaciones del derecho propio mapuche, vol. III, tomo II. En http://www. serindigena.org/libros_digitales/cvhynt/v_ iii/t_ _ii/v3 t2_c3-NEWEN.html (acceso 16.03.2015).

LEÓN SOLÍS, L. 1991. Comercio, trabajo y contacto interétnico en las fronteras de Chile, Cuyo y Buenos Aires, 1750-1800. Runa XIX. Buenos Aires.

LIGHTFOOT, K. y A. MARTÍNEZ. 1995. Frontiers and boundaries in archaeological perspective. Annual Review of Anthropology 24: 471-492.

MANDRINI, R. 1987. La sociedad indígena de las pampas en el siglo XIX. En Antropología, M. Lischetti (Comp.), pp. 311-333. EUDEBA, Buenos Aires.

MANDRINI, R. y S. ORTELLI. 1992. Volver al país de los araucanos. Sudamericana, Buenos Aires.

MANSILLA, L. 2008 [1870]. Una excursión a los indios ranqueles. Gradifco, Argentina.

MARINI DE DÍAZ ZORITA, M. C. 1979. El avance de la frontera. Vias de circulación: las rastrilladas. Universidad Nacional de La Pampa. Fac. Cs. Humanas, Argentina.

MAZZANTI, D. 2007. Arqueología de las relaciones interétnicas posconquista en las sierras de Tandilia. Tesis Doctoral. FFyL, UBA, Buenos Aires.

MERA C. R., B. MILLE, D. MUNITA y V. FIGUEROA. 2015. Copper earrings in la Araucanía: earliest evidence of metal usage in southern Chile. Latin American Antiquity 26(1): 106-119.

MOLINARI, R. 1997. Lo pasado, ¿pisado? Precirculados de las I Jornadas de Investigación y Conservación en el Parque Nacional Lihué Calel: 23-24. Administración de Parques Nacionales. Secretaría de Recursos Naturales y Desarrollo Sustentable. Presidencia de la Nación. 10 y 11 de julio de 1997. Santa Rosa, La Pampa.

MUSAUBACH, M. G. y M. BERÓN. 2012. Cocinando en ollas en la pampa occidental. Datos desde la etnohistoria, el registro arqueológico y la arqueobotánica. En Las manos en la masa. Arqueologías, Antropologías y otras historias de la alimentación en Suramérica, M. del Pilar Babot, M. Marschoff y F. Pazzarelli (Eds.), 
pp. 605-626. Universidad Nacional de Córdoba, FFyH; Museo de Antropología UNC - Instituto Superior de Estudios Sociales UNT, Córdoba.

MUSAUBACH, M. G. y M. BERÓN. 2016. El uso de recursos vegetales entre los cazadores recolectores de la Pampa Occidental argentina. Latin American Antiquity 27(3):397-413.

MUSAUBACH, M. G., R. MERA, M. BERÓNy D. MUNITA. 2015. Análisis arqueobotánicos comparativos en challas de La Araucanía y La Pampa. Presentado en V Encuentro de Arqueología del Centro Chile/Argentina. 25-27 de noviembre 2015. Universidad Alberto Hurtado, Fac. de Cs. Sociales, Santiago de Chile.

NACUZZI L. 2005. Identidades Impuestas. Tehuelches, aucasy pampas en el norte de la Patagonia. Serie publicaciones, Sociedad Argentina de Antropología. Buenos Aires.

NACUZZI L. y C. LUCAIOLI. 2014. Perspectivas antropológicas para el análisis histórico de las fronteras. En Pueblos Indigenas, Estados Nacionales y fronteras. Tensiones y paradojas de los procesos de transición contemporáneos en América Latina. Trinchero, Campos Muñoz y Valverde (Coords.), pp. 27-71. Editorial de la Facultad de Filosofía y Letras (UBA). Buenos Aires, Argentina.

NEME, G. y A. GIL. 2005. Aportes para la discusión del intercambio en el sur de Mendoza. XVI Congreso Nacional de Arqueología Chilena, pp. 317-326.

NICOLETTI, M. A. y P. NÚÑEZ. 2013. Introducción. En Araucanía - Norpatagonia: la territorialidad en debate. Perspectivas ambientales, culturales, sociales, políticas y económicas, M. A. Nicoletti y P. Núñez (Comps.), pp. 6-12. Instituto de Investigaciones en Diversidad Cultural y Procesos de Cambio. Universidad Nacional de Río Negro, Bariloche.

PARKER, B. 2006. Toward an understanding of Borderland processes. American Antiquity 71(1): 77-100.

PIANA, E. 1979. El agua y los malones: represas aborígenes en La Pampa. Universidad Nacional de La Pampa. Fac. de Cs. Humanas, 17 pp. Santa Rosa, La Pampa.

PIANA, E. 1981. Toponimia y arqueología del siglo XIX en La Pampa, EUDEBA, 291 pp. Buenos Aires.

RADOVICH, J. C. 2003. Impacto Social de grandes aprovechamientos hidroenergéticos sobre comunidades rurales de norpatagonia. Tesis Doctoral. FFyL-UBA, Buenos Aires.

SALAZAR SICILIANO, G. y M. BERÓN. 2013. Diacríticos identitarios en las relaciones transcordilleranas. Evidencias de interacción social y cultural entre el centro de Argentina, centro-oeste de Neuquén y la Araucanía chilena. En Araucanía-Norpatagonia: la territorialidad en debate. Perspectivas ambientales, culturales, sociales, políticas y económicas, M. A. Nicoletti y P. Núñez (Comps.), pp. 191-209. Instituto de Investigaciones en Diversidad Cultural y Procesos de Cambio - CONICET - UNRN. E-Book primera edición, San Carlos de Bariloche.

STERN, C. R., C. GARCÍA, X. NAVARRO y J. MUÑOZ. 2009. Fuentes y distribución de diferentes tipos de obsidianas en sitios arqueológicos del centro-sur de Chile (38-44 S). Magallania 37(19): 179-192.

STERN, C. R., C. GARCÍA, X. NAVARRO y J. MUÑOZ. 2009. Fuentes y distribución de diferentes tipos de obsidianas en sitios arqueológicos del centro-sur de Chile (38-44 ${ }^{\circ}$ ). Magallania 37(1): 179-192.

THACKERAY, A. 2005. Perspectives on Later Stone Age HunterGatherer Archaeology in Arid Southern Africa. En Archaeological Perspectives, P. Veth, M. Smith y Peter Hiscock (Eds.), pp. 161176. Blackwell Publishing Ltd., Australia.

THOMAS, K. y J. KNOX. 1994. Routes of passage: later prehistoric settlement and exploitation of a frontier region in northwestern Pakistan. Institute of Archaeology Bulletin 31: 89-103.

VETH, P. 1995. Aridity and settlement in northwest Australia.Antiquity 69 (265): 733-746.

VILLALOBOS, S. 1989. Guerra y paz en la Araucanía: periodificación. EnAraucanía. Temas de Historia Fronteriza. Villalobos, S. et al. (Eds.), pp. 7-30. Serie Quinto Centenario. Ediciones Universidad de La Frontera, Temuco.

VILLAR, D. y JIMÉNEZ J. F. 2003. La tempestad de la guerra: Conflictos indígenas y circuitos de intercambio. Elementos para una periodización (Araucanía y las Pampas, 1780-1840). En Las fronteras hispanocriollas del mundo indígena latinoamericano en los siglos XVIII-XIX. Un estudio comparativo, R. J. Mandrini y C. D. Paz (Comps.), pp. 123-171. Tandil: IEHS, Universidad Nacional del Centro de la Provincia de Buenos Aires-CEHIR, Universidad Nacional del Comahue, Departamento de Humanidades, Universidad Nacional del Sur.

WEISS, L., J. ENGELMAN, S. VALVERDE. 2013. Pueblos indígenas urbanos en Argentina: un estado de la cuestión. Pilquen. Sección Ciencias Sociales. Año XV, 16(1): 1-15.

ZAVALA CEPEDA, J. M. 2011. Los mapuches del siglo XVIII. Dinámica interétnica y estrategias de resistencia. Universidad Católica de Temuco, Santiago de Chile. 